Cochrane Database of Systematic Reviews

\title{
Haemophilus influenzae oral vaccination for preventing acute exacerbations of chronic bronchitis and chronic obstructive pulmonary disease (Review)
}

Teo E, Lockhart K, Purchuri SN, Pushparajah J, Cripps AW, van Driel ML

Teo E, Lockhart K, Purchuri SN, Pushparajah J, Cripps AW, van Driel ML.

Haemophilus influenzae oral vaccination for preventing acute exacerbations of chronic bronchitis and chronic obstructive pulmonary disease.

Cochrane Database of Systematic Reviews 2017, Issue 6. Art. No.: CD010010.

DOI: 10.1002/14651858.CD010010.pub3. 
TABLE OF CONTENTS

HEADER 1

ABSTRACT

PLAIN LANGUAGE SUMMARY

SUMMARY OF FINDINGS

BACKGROUND

OBJECTIVES

METHODS

RESULTS

Figure 1.

Figure 2.

Figure 3.

Figure 4.

Figure 5.

DISCUSSION

AUTHORS' CONCLUSIONS

ACKNOWLEDGEMENTS

REFERENCES

CHARACTERISTICS OF STUDIES

DATA AND ANALYSES

Analysis 1.1. Comparison 1 Primary outcomes, Outcome 1 Exacerbations (number of exacerbations/person).

Analysis 1.2. Comparison 1 Primary outcomes, Outcome 2 Mortality (deaths during trial period).

Analysis 2.1. Comparison 2 Secondary outcomes, Outcome 1 Prescriptions (number of courses/person/year).

Analysis 2.2. Comparison 2 Secondary outcomes, Outcome 2 Adverse events (number of adverse events/person). ADDITIONAL TABLES

APPENDICES

WHAT'S NEW

CONTRIBUTIONS OF AUTHORS

DECLARATIONS OF INTEREST

SOURCES OF SUPPORT

DIFFERENCES BETWEEN PROTOCOL AND REVIEW

INDEX TERMS 
[Intervention Review]

\section{Haemophilus influenzae oral vaccination for preventing acute exacerbations of chronic bronchitis and chronic obstructive pulmonary disease}

Edward Teo $1,2,3$, Kathleen Lockhart ${ }^{4}$, Sai Navya Purchuri ${ }^{5}$, Jennifer Pushparajah 6 , Allan W Cripps ${ }^{7}$, Mieke L van Driel ${ }^{8,9,10}$

1Emergency Department, Concord Repatriation General Hospital, Sydney, Australia. 2School of Medicine, Griffith University, Gold Coast, Australia. ${ }^{3}$ School of Medicine, The University of Queensland, Brisbane, Australia. ${ }^{4}$ Townsville Hospital, Douglas, Australia. ${ }^{5}$ Logan Hospital, Logan, Australia. ${ }^{6}$ Waitakere Hospital, Auckland, New Zealand. ${ }^{7}$ School of Medicine, Menzies Health Institute Queensland, Griffith University, Meadowbrook, Australia. 8Primary Care Clinical Unit, Faculty of Medicine, The University of Queensland, Brisbane, Australia. ${ }^{9}$ Centre for Research in Evidence-Based Practice (CREBP), Bond University, Gold Coast, Australia. ${ }^{10}$ Department of Family Medicine and Primary Health Care, Ghent University, Ghent, Belgium

Contact address: Edward Teo, Emergency Department, Concord Repatriation General Hospital, Hospital Road, Concord, Sydney, New South Wales, 2137, Australia. eteo@outlook.com.

Editorial group: Cochrane Acute Respiratory Infections Group.

Publication status and date: New search for studies and content updated (no change to conclusions), published in Issue 6, 2017.

Citation: Teo E, Lockhart K, Purchuri SN, Pushparajah J, Cripps AW, van Driel ML. Haemophilus influenzae oral vaccination for preventing acute exacerbations of chronic bronchitis and chronic obstructive pulmonary disease. Cochrane Database of Systematic Reviews 2017, Issue 6. Art. No.: CD010010. DOI: 10.1002/14651858.CD010010.pub3.

Copyright @ 2017 The Cochrane Collaboration. Published by John Wiley \& Sons, Ltd.

\section{A B S T R A C T}

\section{Background}

Chronic bronchitis and chronic obstructive pulmonary disease (COPD) are serious conditions in which patients are predisposed to viral and bacterial infections resulting in potentially fatal acute exacerbations. Chronic obstructive pulmonary disease is defined as a lung disease characterised by obstruction to lung airflow that interferes with normal breathing. Antibiotic therapy has not been particularly useful in eradicating bacteria such as non-typeable Haemophilus influenzae (NTHi) because they are naturally occurring flora of the upper respiratory tract in many people. However, they can cause opportunistic infection. An oral NTHi vaccine has been developed to protect against recurrent infective acute exacerbations in chronic bronchitis.

\section{Objectives}

To assess the effectiveness of an oral, whole-cell NTHi vaccine in protecting against recurrent episodes of acute exacerbations of chronic bronchitis and COPD in adults. To assess the effectiveness of NTHi vaccine in reducing NTHi colonising the respiratory tract during recurrent episodes of acute exacerbations of COPD.

\section{Search methods}

We searched the following databases: the Cochrane Central Register of Controlled Trials (CENTRAL) (2017, Issue 1), MEDLINE (1946 to January 2017), Embase (1974 to January 2017), CINAHL (1981 to January 2017), LILACS (1985 to January 2017), and Web of Science (1955 to January 2017). We also searched trials registries and contacted authors of trials requesting unpublished data.

\section{Selection criteria}

We included randomised controlled trials comparing the effects of an oral monobacterial NTHi vaccine in adults with recurrent acute exacerbations of chronic bronchitis or COPD when there was overt matching of the vaccine and placebo groups on clinical grounds. The selection criteria considered populations aged less than 65 years and those older than 65 years.

Haemophilus influenzae oral vaccination for preventing acute exacerbations of chronic bronchitis and chronic obstructive pulmonary 


\section{Data collection and analysis}

Two review authors independently assessed trial quality and extracted data from original records and publications for incidence and severity of bronchitis episodes and carriage rate of NTHi measured in the upper respiratory tract, as well as data relevant to other primary and secondary outcomes.

\section{Main results}

We identified six placebo-controlled randomised controlled trials with a total of 557 participants. These trials investigated the efficacy of enteric-coated, killed preparations of $H$ influenzae in populations prone to recurrent acute exacerbations of chronic bronchitis or COPD. The vaccine preparation and immunisation regimen in all trials consisted of at least three courses of formalin-killed $H$ influenzae in entericcoated tablets taken at intervals (e.g. days 0,28 , and 56). Each course generally consisted of two tablets taken after breakfast over three consecutive days. In all cases the placebo groups took enteric-coated tablets containing glucose. Risk of bias was moderate across the studies, namely due to the lack of information provided about methods and inadequate presentation of results.

Meta-analysis of the oral NTHi vaccine showed a small, non-statistically significant reduction in the incidence of acute exacerbations of chronic bronchitis or COPD (risk ratio (RR) $0.79,95 \%$ confidence interval $(\mathrm{Cl}) 0.57$ to $1.10 ; \mathrm{P}=0.16$ ). There was no significant difference in mortality rate between the vaccine and placebo groups (odds ratio $(\mathrm{OR}) 1.62,95 \% \mathrm{Cl} 0.63$ to $4.12 ; \mathrm{P}=0.31$ ).

We were unable to meta-analyse the carriage levels of NTHi in participants as each trial reported this result using different units and tools of measurement. Four trials showed no significant difference in carriage levels, while two trials showed a significant decrease in carriage levels in the vaccinated group compared with the placebo group.

Four trials assessed severity of exacerbations measured by requirement for antibiotics. Three of these trials were comparable and when meta-analysed showed a statistically significant $80 \%$ increase in antibiotic courses per person in the placebo group (RR $1.81,95 \% \mathrm{Cl} 1.35$ to 2.44; $\mathrm{P}<0.001)$. There was no significant difference between the groups with regard to hospital admission rates $(\mathrm{OR} 0.96,95 \% \mathrm{Cl} 0.13$ to $7.04 ; \mathrm{P}=0.97$ ). Adverse events were reported in five trials but were not necessarily related to the vaccine; a point estimate is suggestive that they occurred more frequently in the vaccine group, however this result was not statistically significant $(\mathrm{RR} 1.43,95 \% \mathrm{Cl} 0.70$ to $2.92 ; \mathrm{P}$ $=0.87$ ). Quality of life was not meta-analysed but was reported in two trials, with results at six months showing an improvement in quality of life in the vaccinated group (scoring at least two points better than placebo).

\section{Authors' conclusions}

Analyses demonstrate that NTHi oral vaccination of people with recurrent exacerbations of chronic bronchitis or COPD does not yield a significant reduction in the number and severity of exacerbations. Evidence was mixed, and the individual trials that showed a significant benefit of the vaccine are too small to advocate widespread oral vaccination of people with COPD.

\section{PLAIN LANGUAGE SUMMARY}

\section{Haemophilus influenzae oral vaccination for preventing acute exacerbations of chronic bronchitis and chronic obstructive pulmonary disease}

\section{Review question}

We reviewed the evidence about the effect of a non-typeable Haemophilus influenzae (NTHi) vaccine in preventing repeated $H$ influenzae infections in people with chronic obstructive pulmonary disease (COPD) or chronic bronchitis.

\section{Background}

People with COPD can have frequent infections that worsen symptoms of their lung disease, that is increased breathlessness, purulent discharge and decompensating oxygen saturations levels, known as an 'acute exacerbation'. The bacteria that most commonly causes this is $\mathrm{H}$ influenzae. Infection with $\mathrm{H}$ influenzae can lead to hospitalisation, and in some cases, death. Preventing these infections with a vaccine could lead to people with COPD having improved outcomes compared to the current practice of treating infections as they arise.

\section{Study characteristics}

The evidence is current to January 2017. We identified six studies with a total of 557 participants. The studies were blinded, placebocontrolled randomised trials that tested how effective the NTHi vaccine is in preventing infections in people over 18 years of age with COPD or chronic bronchitis. In all six trials, both the vaccine and placebo group were given at least three courses of tablets at regular intervals over a period of three to 12 months. Generally, the baseline demographics of participants across the included studies shared similar characteristics (such as diet, lifestyle, and living conditions) to other high-income countries. Ages ranged between 40 and 80 years. The studies counted the number of infections the participants experienced, levels of respiratory tract bacteria, deaths, side effects, hospital admissions, or treatment with antibiotics.

\section{Key results}

Haemophilus influenzae oral vaccination for preventing acute exacerbations of chronic bronchitis and chronic obstructive pulmonary 
The NTHi vaccine had no significant impact on reducing the number of acute exacerbations experienced by people with COPD. There was no significant difference in mortality rate between the vaccine and placebo groups, and the reported deaths in the vaccinated group were not attributed to the vaccine.

The levels of $H$ influenzae bacteria found in the respiratory tracts of participants did not differ between the vaccine and placebo groups. Due to inconsistencies of measurement between the trials, we were not able to compare the studies against one another.

Antibiotics, which can be an indicator of severe infection, were significantly more commonly prescribed in the placebo group. Evidence of hospital admissions showed that there was no difference in the likelihood of being hospitalised in either the vaccine or the placebo group. Two trials studying quality of life found that vaccinated participants generally had a better quality of life, but these results were measured differently and so could not be compared.

Five trials reported adverse effects, but there was no particular association with either the vaccine or placebo group. Further research is needed to define adverse effects as outcome measures for more definitive analyses regarding vaccine side effects.

\section{Quality of the evidence}

The studies were well conducted with moderate risk of bias. The main limitation of this review was the lack of consistency regarding the definitions and outcome measures among the individual studies, which affected the overall synthesis and interpretation of the results. Fewer participants may mean the results are more likely to be affected by chance. One trial had more participants than the other five trials combined, and it contributed more to the final analysis. There was moderate heterogeneity (the studies showed quite different results) when this study was included in the analysis, especially in numbers of infections. However, the results were consistent and did not change when this study was removed from the analysis.

\section{Conclusion}

We concluded after reviewing the relevant studies that the $H$ influenzae vaccine taken orally in people with chronic bronchitis and COPD does not have a significant reduction in the number and severity of acute exacerbations. 


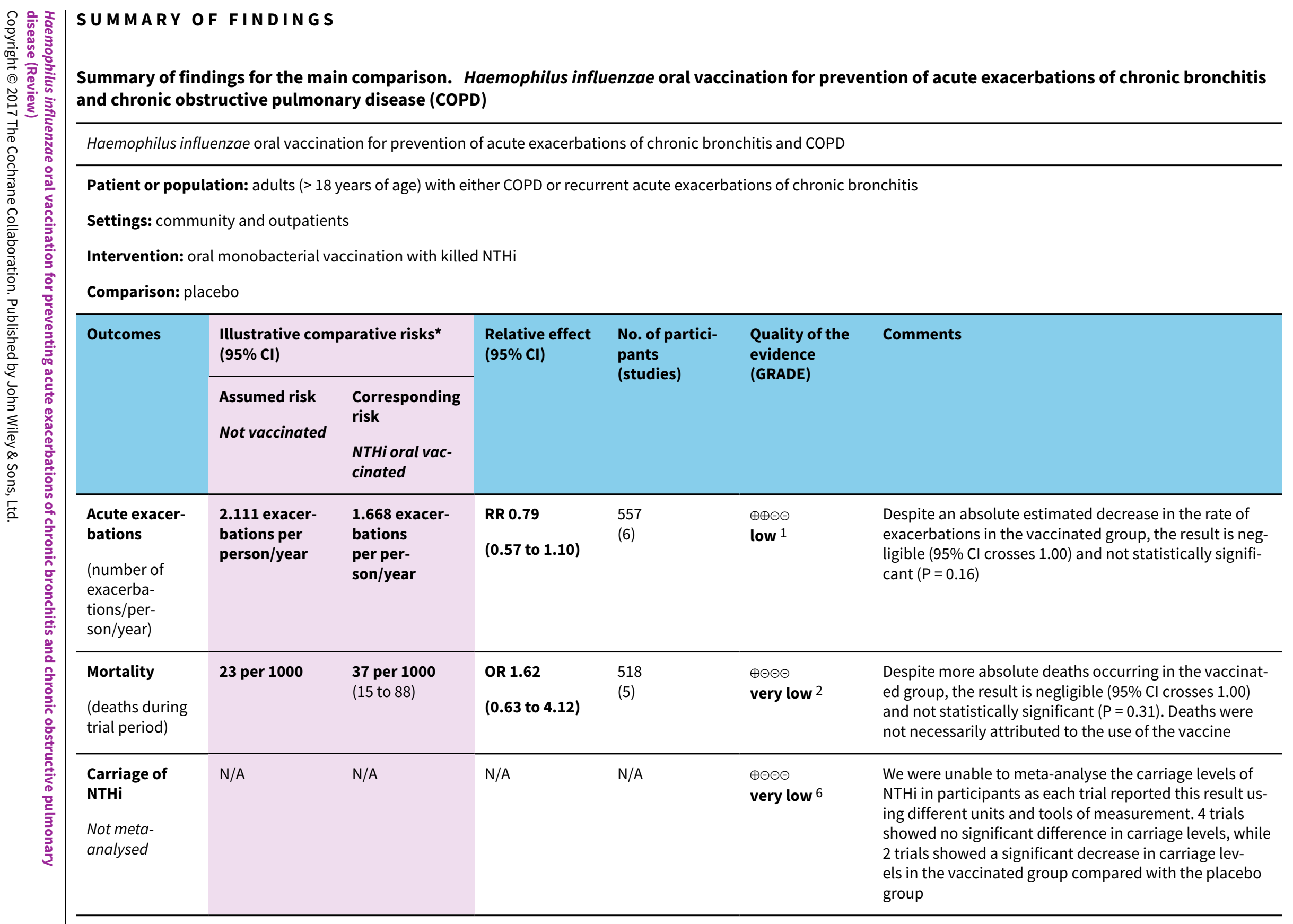




\begin{tabular}{|c|c|c|c|c|c|c|}
\hline $\begin{array}{l}\text { Antibiotic pre- } \\
\text { scriptions } \\
\text { (number of } \\
\text { courses/per- } \\
\text { son/year) } \\
{ }^{\star \star} \text { Corticos- } \\
\text { teroids not } \\
\text { meta-analysed }\end{array}$ & $\begin{array}{l}5.723 \\
\text { prescriptions } \\
\text { per per- } \\
\text { son/year }\end{array}$ & $\begin{array}{l}3.162 \\
\text { prescriptions } \\
\text { per per- } \\
\text { son/year }\end{array}$ & $\begin{array}{l}\text { RR } 1.81 \\
\text { (1.35 to } 2.44 \text { ) }\end{array}$ & $\begin{array}{l}142 \\
(3)\end{array}$ & $\begin{array}{l}\oplus \oplus \Theta \Theta \\
\text { low } 3\end{array}$ & $\begin{array}{l}\text { Courses of antibiotics were found to be prescribed in the } \\
\text { placebo group at a rate approximately } 80 \% \text { greater than } \\
\text { in the vaccinated group }(\mathrm{P}<0.001) \\
\text { (Note that a RR }>1.0 \text { here indicates more antibiotics be- } \\
\text { ing prescribed to participants in the placebo group, i.e. } \\
\text { RR } 1.81 \text { corresponds to an approximately } 80 \% \text { increased } \\
\text { rate of antibiotic prescriptions when not receiving the } \\
\text { vaccine. The placebo group is being compared to the } \\
\text { vaccine group in this instance to attempt to demon- } \\
\text { strate how many more antibiotics are required in those } \\
\text { not vaccinated) } \\
\text { **2studies reported corticosteroid use, however due to } \\
\text { differences in units of measurement, these results could } \\
\text { not be meta-analysed }\end{array}$ \\
\hline $\begin{array}{l}\text { Hospital ad- } \\
\text { missions } \\
\text { (number of par- } \\
\text { ticipants hospi- } \\
\text { talised during } \\
\text { trial period) }\end{array}$ & $\mathrm{N} / \mathrm{A}$ & $\mathrm{N} / \mathrm{A}$ & $\mathrm{N} / \mathrm{A}$ & $\mathrm{N} / \mathrm{A}$ & $\begin{array}{l}\oplus \oplus \oplus \ominus \\
\text { moderate } 4\end{array}$ & $\begin{array}{l}\text { Hospital admissions was not meta-analysed due to dif- } \\
\text { fering units of measurement by the } 2 \text { trials that reported } \\
\text { this finding. Notwithstanding that pooling the data for } \\
\text { the } 2 \text { trials would have yielded high heterogeneity. Hos- } \\
\text { pital admissions were not necessarily attributable to the } \\
\text { vaccine }\end{array}$ \\
\hline $\begin{array}{l}\text { Adverse events } \\
\text { (number of ad- } \\
\text { verse events/ } \\
\text { person/year) }\end{array}$ & $\begin{array}{l}0.319 \\
\text { adverse } \\
\text { events } \\
\text { per per- } \\
\text { son/year }\end{array}$ & $\begin{array}{l}0.456 \\
\text { adverse } \\
\text { events } \\
\text { per per- } \\
\text { son/year }\end{array}$ & $\begin{array}{l}\text { RR } 1.43 \\
\text { (0.70 to 2.92) }\end{array}$ & $\begin{array}{l}484 \\
(5)\end{array}$ & $\begin{array}{l}\oplus \oplus \ominus \ominus \\
\text { low } 5\end{array}$ & $\begin{array}{l}\text { Despite an estimated absolute increased rate of adverse } \\
\text { events in the vaccinated group, the result is negligible } \\
(95 \% \mathrm{Cl} \text { crosses } 1.00) \text { and not statistically significant ( } P \\
=0.61) \text {. Adverse events were not necessarily attributable } \\
\text { to the vaccine }\end{array}$ \\
\hline $\begin{array}{l}\text { Quality of life } \\
\text { Not meta- } \\
\text { analysed }\end{array}$ & $\mathrm{N} / \mathrm{A}$ & $\mathrm{N} / \mathrm{A}$ & $\mathrm{N} / \mathrm{A}$ & $\mathrm{N} / \mathrm{A}$ & $\begin{array}{l}\oplus \ominus \ominus \ominus \\
\text { very low } 6\end{array}$ & $\begin{array}{l}\text { Quality of life was not meta-analysed due to differ- } \\
\text { ing units of measurement, but was reported in } 2 \text { tri- } \\
\text { als, which showed an improvement at } 6 \text { months in the } \\
\text { vaccine group (scoring at least } 2 \text { points better than the } \\
\text { placebo group; significance unknown) }\end{array}$ \\
\hline
\end{tabular}

*The basis for the assumed risk (e.g. the median control group risk across studies) is provided in the footnotes. The corresponding risk (and its $95 \%$ confidence interval (CI)) is based on the assumed risk in the comparison group and the relative effect of the intervention (and its 95\% $\mathrm{Cl}$ ).

Cl: confidence interval; N/A: not applicable; NTHi: non-typeable Haemophilus influenzae; OR: odds ratio; RR: risk ratio

GRADE Working Group grades of evidence

High quality: Further research is very unlikely to change our confidence in the estimate of effect.

Moderate quality: Further research is likely to have an important impact on our confidence in the estimate of effect and may change the estimate.

Low quality: Further research is very likely to have an important impact on our confidence in the estimate of effect and is likely to change the estimate. 


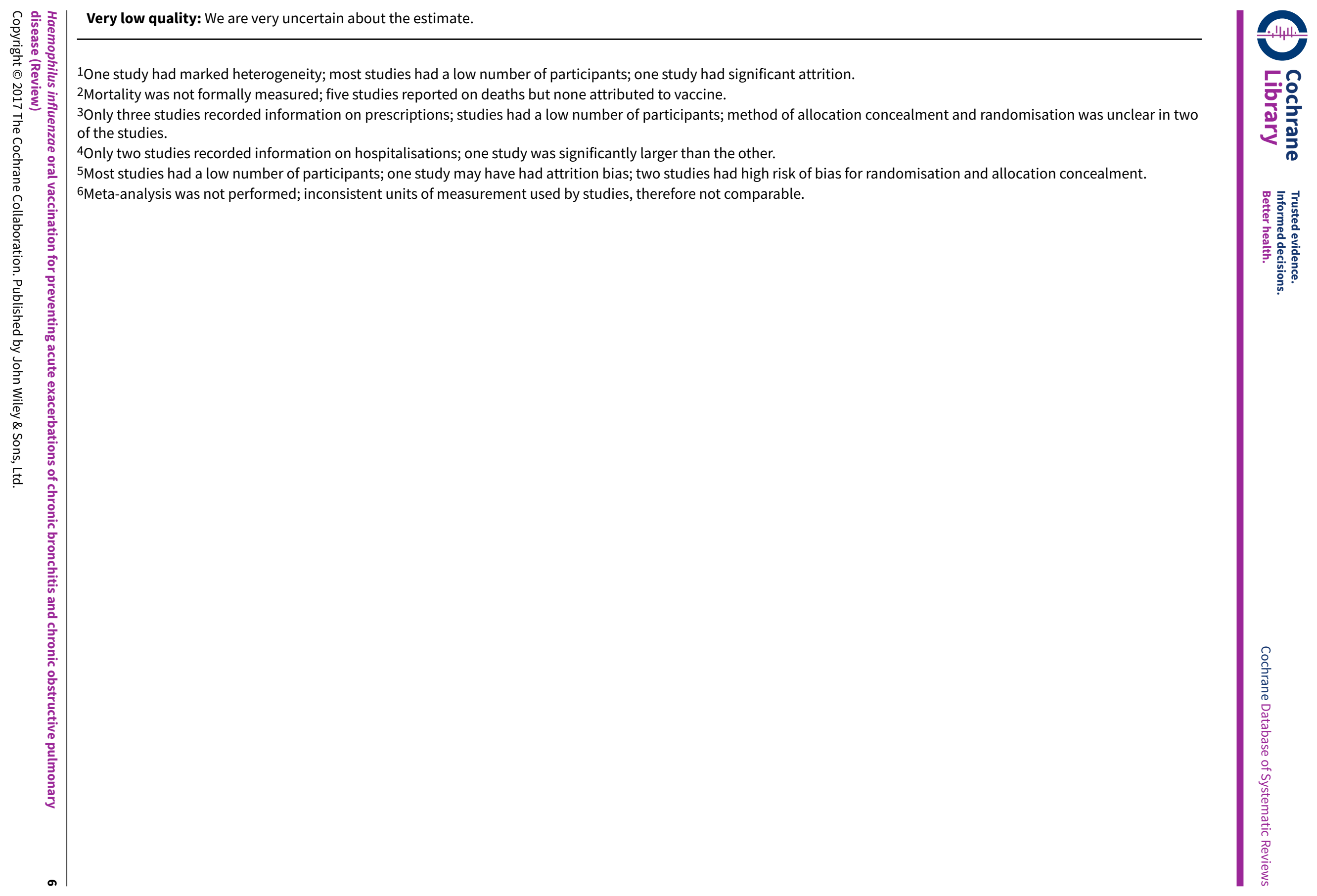




\section{B A C K G R O U N D}

\section{Description of the condition}

Chronic obstructive pulmonary disease (COPD) is characterised by persistent airflow limitation that is progressive and associated with an enhanced chronic inflammatory response. The chronic airflow limitation characteristic of COPD is caused by a mixture of small airways disease (obstructive bronchiolitis) and gas-exchange impediment through parenchymal destruction (emphysema). The changes associated with an inflammatory response include cellular infiltrate, mucus secretion, and structural remodelling, which diminish the overall ability of the airways to remain patent during expiration. This limitation in airflow, as a measurement of disease severity, is best measured and assessed by spirometry (COPD is defined as the forced expiratory volume in one second $\left(\mathrm{FEV}_{1}\right)$ being lower than $80 \%$ of the predicted normal) (GOLD 2011; Otczyk 2011).

Chronic bronchitis is clinically defined by the presence of cough and sputum production for at least three months in each of two consecutive years. It is an independent disease entity that may precede or follow the development of airflow limitation and may be associated with the development or acceleration of fixed airflow limitation, or both, that is COPD. Chronic bronchitis may exist in patients with normal spirometry (GOLD 2011). While patients can remain undiagnosed and have no clinical evidence of a lung disease until they present with advanced COPD, many have a history of symptomatic disease, evidenced as chronic cough and sputum (chronic bronchitis) and/or recurrent episodes of acute wheezy bronchitis and/or late-onset reversible airways disease (intrinsic asthma). Currently, the diagnosis of an acute exacerbation is based entirely on clinical presentation. There is no consensus regarding an objective measurement of an exacerbation (GOLD 2011). The relationship between these entities is complex and not well understood, with no obligatory linkage with COPD, but has the capacity to progress to COPD (Otczyk 2011).

An acute exacerbation is defined as an acute event characterised by worsening of the patient's respiratory symptoms beyond normal daily variations, and can lead to a change in medication (GOLD 2011). The best predictors of exacerbations are a history of previously treated exacerbations and worsening airflow limitation (GOLD 2011). Exacerbations may be triggered by bacterial or viral infection (or both simultaneously), environmental pollutants, or as yet undetermined factors. The characteristic response is increased inflammation resulting in increased purulent sputum production, hyperinflation, and gas trapping, with reduced expiratory flow, thus accounting for the dyspnoea associated with these episodes (GOLD 2011). Whilst participants with an atopic constitution (hypersensitive to allergens) may be predisposed to developing COPD, it should be recognised that bacterial colonisation of damaged airways plays an important pathogenic role. In participants with established obstructive lung disease, acute attacks of infection are a major cause of morbidity and mortality.

The Global Initiative for Chronic Obstructive Lung Disease (GOLD) guidelines estimate the prevalence of COPD to range from $7.8 \%$ to $19.7 \%$ of the population worldwide (GOLD 2011). Chronic obstructive pulmonary disease is very prominent in populations of smokers and ex-smokers. However, estimates of prevalence in people who have never smoked range from 3\% to $11 \%$ (GOLD 2011). The World Health Organization (WHO) estimates that $5 \%$ of all deaths globally can be attributed to COPD, with the disease becoming the third leading cause of death by 2030 (WHO 2013). Whilst epidemiological information regarding COPD comes from high-income countries, $90 \%$ of COPD deaths occur in low- and middle-income countries (WHO 2013).

The management of acute exacerbations focuses on treating triggers (including infections) and relieving symptoms with bronchodilators, glucocorticoids, and antibiotics. Prevention of further exacerbations focuses on vaccination of influenza and pneumococcus strains (WHO 2013). A recent Cochrane review on the use of prophylactic antibiotics for COPD exacerbations concluded that there was a reduction in the number of participants experiencing exacerbations with continuous macrolide antibiotic use. The number needed to treat to prevent one exacerbation was eight. These promising findings need to be weighed against the risks from long-term antibiotic use, such as side effects of medications and bacterial resistance (Herath 2013).

Bacterial and viral causative agents have been identified and may coexist in a benign or pathogenic capacity; because of this, the specific microbiological aetiology of acute exacerbations in chronic bronchitis and COPD patients remains a matter of debate. The pathogens responsible for these acute exacerbations are often found in the person's upper respiratory tract, and (opportunistic) infections are caused by an upset in the balance of the host-parasite relationship. Bacterial colonisation is most common and more severe compared to viral infections. The upper respiratory tract is commonly home to Staphylococcus epidermidis,Staphylococcus aureus,Streptococcus pneumoniae,Streptococcus pyogenes, $H$ influenzae, andNeisseria meningitides. The lower respiratory tract is normally virtually free of micro-organisms, due to physiological clearance mechanisms (e.g. mucociliary clearance). However, should these systems become damaged (as is the case in COPD or bronchitis patients), pathogens such as non-typeable $H$ influenzae (NTHi) or Pseudomonas aeruginosa are usually the ones to colonise these sites (Butt 1990). Non-typeable $H$ influenzae is of particular importance in this scenario because of its frequent and predominant pattern of mucosal colonisation of the respiratory tract. Higher levels of immunoglobulin $\mathrm{E}$ (IgE) have been detected in the serum of people with COPD, and it has been observed that NTHi triggers histamine release. This process occurs through both IgE- and non-IgEdependent mechanisms from cells contained within the respiratory mucosal sensitised to the bacterium. These findings demonstrate that NTHi may also play a role in the development of the reversible component of airways obstruction in COPD. Immediate hypersensitivity via IgE antibacterial antibodies to colonising bacteria may contribute to bronchial disease progression and severity (Otczyk 2011). As these conditions have been associated with high numbers of $\mathrm{NTHi}$, the vaccine was considered to be relevant in the prevention of exacerbation frequency and severity.

\section{Description of the intervention}

Various treatment strategies have been attempted including immuno-stimulatory agents made from bacterial extracts, such as OM-85 BV, and antibiotics. While OM-85 BV appears not to affect the occurrence of acute exacerbations of bronchitis, it reduces the severity of the exacerbation ( $55 \%$ fewer total days of hospitalisation compared to placebo) (Collet 1997). Conventional antibiotic therapy has not been particularly helpful, possibly due to the inability to effectively clear respiratory flora such as NTHi,

Haemophilus influenzae oral vaccination for preventing acute exacerbations of chronic bronchitis and chronic obstructive pulmonary 
which leads to further growth and sepsis (Foxwell 1998a; Murphy 1992; Van Alphen 1995). Recent studies have identified a role for antibiotics in the treatment of COPD (Albert 2011; Macfarlane 2001). Although significant differences in the incidence of exacerbation were noted between groups, the long-term effect on microbial resistance was not reported. This underscores the importance of exploring vaccination as a prophylactic treatment of COPD.

An alternative strategy is mucosal immunisation. Successful vaccines for $H$ influenzae depend on immunity stimulation against the type-specific polysaccharide capsule of Haemophilus influenzae $B$ (Hib). Following the development of successful vaccines for infections caused by Hib, attention is now focused on developing a vaccine for NTHi. Accordingly, an oral, whole-cell NTHi vaccine has been developed to prevent NTHi infections, which is the focus of this review.

Oral immunisation reduced bacterial loads in participants who were chronically colonised, and NTHi-specific cellular responses were detected in white blood cells (lymphocytes) in the serum (Otczyk 2010). This suggests that a NTHi vaccine may be useful, as it demonstrates that mucosal immunisation can be used therapeutically to enhance or modify an immune response to improve the outcomes of an established chronic mucosal infection (Otczyk 2010).

\section{How the intervention might work}

The vaccine is believed to be most effectively absorbed through the gastrointestinal tract in order to trigger an immune response. The killed NTHi cells of the vaccine are coated with formalin to protect it from gastric degradation, thus enabling it to access the M-cells of the gut mucosal immune system through patternrecognition receptors that are designed to identify pathogenassociated molecular patterns (i.e. PRR-PAMP interactions). Human and animal studies support the hypothesis that oral NTHi immunisation stimulates T-cells in the Peyer's patches of the gastrointestinal tract (Foxwell 1998a). The T-cells, upon stimulation from the vaccine, migrate to the respiratory system via afferent lymphatics and blood, where they are further stimulated by bacteria in the bronchial mucosa. Cytokines are secreted from the stimulated T-cells to further increase immune activity. This results in increased recruitment and up-regulation of neutrophil white blood cells into the bronchial space, which in turn assists in clearing bacteria through phagocytosis and thus reducing the bacterial load (Clancy 2011).

However, it must be noted that this form of immunisation does not trigger classical mucosal immunoglobulin A responses, but rather by the means outlined above. Nonetheless, an oral vaccine of inactivated NTHi makes use of a 'physiological protective loop' to improve airway immune function. The vaccine is consumed orally and digested within the gastrointestinal tract, which triggers an innate immune response in the respiratory tract. Through a specific activation of immune cells (in the gastrointestinal tract) this initiates non-specific protection (in the airways). Pathways that stimulate T-helper 17 immune cells responsible for airway protection then generate an increased white blood cell responsiveness to all pathogens in the respiratory tract (Clancy 2011).

\section{Why it is important to do this review}

Chronic obstructive pulmonary disease is a major cause of morbidity and mortality. Acute exacerbations of COPD reflect intense intrabronchial inflammation, where recurrent exacerbations are linked to worsening of airflow obstruction and health status of the individual. Acute exacerbations of COPD can be fatal. Recent studies demonstrate that oral immunotherapy with NTHi reduces the level of bacterial colonisation in the airways as well as the incidence and severity of acute exacerbations (Otczyk 2011).

As chronic antibiotic therapy is not particularly feasible, an oral, whole-cell vaccination for NTHi has been developed to reduce morbidity and mortality in people at risk. Clinical benefit has been reflected in reduced incidence and severity of exacerbations in a number of studies. A review of trials that use oral NTHi wholecell vaccinations should evaluate if oral immunotherapy provides a significant therapeutic advance in limiting damage in COPD and may highlight the pathogenic role of bacterial colonisation of damaged airways.

This is an update of a Cochrane review first published in 1998 and last updated in 2006 (Foxwell 2006). The previous authors concluded that participants with recurrent bronchitis vaccinated in the autumn had a decreased incidence and severity of their exacerbations during winter.

\section{OB JECTIVES}

To assess the effectiveness of an oral, whole-cell NTHi vaccine in protecting against recurrent episodes of acute exacerbations of chronic bronchitis and COPD in adults. To assess the effectiveness of NTHi vaccine in reducing NTHi colonising the respiratory tract during recurrent episodes of acute exacerbations of COPD.

\section{METHODS}

\section{Criteria for considering studies for this review}

\section{Types of studies}

Randomised controlled trials investigating the efficacy of an oral monobacterial NTHi vaccine in people predisposed to acute exacerbations of chronic bronchitis and COPD.

\section{Types of participants}

Adults (18 years or older) with acute exacerbations of chronic bronchitis or COPD.

\section{Types of interventions}

All trials comparing a monobacterial NTHi orally administered vaccine with a placebo. We included trials where bronchodilators, analgesics, and antibiotics were used in both active and placebo groups.

\section{Types of outcome measures}

\section{Primary outcomes}

1. Incidence of acute exacerbations of chronic bronchitis or COPD.

2. Mortality. 


\section{Secondary outcomes}

1. Carriage level of NTHi in the respiratory tract (including nasopharyngeal swabs, sputum samples, nasopharyngeal aspirates).

2. Numbers of prescriptions for antibiotics and corticosteroids in the trial and follow-up periods (including hospital admissions) as an indication of severity of acute exacerbations.

3. Any associated adverse side effects from the NTHi vaccination, measurable from symptomology and participant reports.

4. Quality of life. A validated tool measurement was required for trials to be included in this review.

\section{Search methods for identification of studies}

\section{Electronic searches}

We searched the Cochrane Central Register of Controlled Trials (CENTRAL) (2017, Issue 1), which includes the Cochrane Acute Respiratory Infections Group's Specialised Register, MEDLINE (1946 to January 2017), Embase (1974 to January 2017), CINAHL (Cumulative Index to Nursing and Allied Health Literature) (1981 to January 2017), LILACS (Latin American and Caribbean Health Sciences Literature) (1985 to January 2017), and Web of Science (1955 to January 2017).

We used the search strategy in Appendix 1 to search MEDLINE and CENTRAL. We combined the MEDLINE search with the Cochrane Highly Sensitive Search Strategy for identifying randomised trials in MEDLINE: sensitivity-maximising version (2008 revision); Ovid format (Lefebvre 2011). We adapted the search strategy to search Embase (see Appendix 2), CINAHL (see Appendix 3), LILACS (see Appendix 4), and Web of Science (see Appendix 5). We used no publication or language restrictions.

\section{Searching other resources}

We searched the clinical trials registers World Health Organization International Clinical Trials Registry Platform (WHO ICTRP) (www.who.int/ictrp/en/) and ClinicalTrials.gov (clinicaltrials.gov/) for completed and ongoing trials (last searched January 2017). We also searched reference lists of included trials and review studies; books related to respiratory tract infections, mucosal immunology, or vaccines; abstracts from respiratory conferences, immunology conferences, microbiology conferences, or vaccine conferences; and sent written enquiries to the authors of major relevant studies and experts in the field. We also contacted pharmaceutical companies to obtain access to unpublished trials.

\section{Data collection and analysis}

\section{Selection of studies}

Two review authors (KL, ET) assessed titles and abstracts retrieved from the search to determine their relevance to the objectives of this review. Any disagreements were resolved through discussion or by consulting a deciding arbiter (MVD). We entered all search results into Review Manager 5 (RevMan 2014).

\section{Data extraction and management}

Two review authors (HH, SNP) designed a data extraction sheet for trial reports, which was pilot tested using sample studies and revised by the other review authors. Two review authors (HH, SNP) then independently extracted data from the reports. We extracted data from each report separately and then combined data in the event of multiple reports for the same study. Any disagreements were resolved through discussion or by consulting a deciding arbiter (MVD).

\section{Assessment of risk of bias in included studies}

Two review authors (KL, JP) independently analysed each trial using Cochrane's tool for assessing risk of bias (Higgins 2011; RevMan 2014), judging each study on the following domains: sequence generation, allocation concealment, blinding, incomplete outcome data, selective outcome reporting, and other potential threats to validity. We rated the risk of bias for each domain as 'high', 'low', or 'unclear' and provided the supporting information that led to that rating. Any disagreements were resolved through discussion or by consulting a deciding arbiter (MVD).

\section{Measures of treatment effect}

1. We presented dichotomous (binary) data as a measure of risk and relative risk by using an odds ratio (OR) or risk ratio (RR) with 95\% confidence intervals (Cls). We calculated the absolute risk reduction (ARR) for consumer comparison against other treatments or non-treatment.

2. We presented continuous data as mean differences (MDs) if the same scale was used or as standardised mean differences (SMDs) if different scales were used with a standard deviation (SD) of the estimate.

3. We looked for quality of life outcomes as measured in the included studies. Quality of life measurements had to be measured using a validated tool. We pooled these outcomes where possible, discussing and summarising them where this was not possible.

4. We have pooled data reported as rates by using the inverse variance method as described in the Cochrane Handbook for Systematic Reviews of Interventions (Higgins 2011).

\section{Unit of analysis issues}

The unit of analysis in our review was the participant.

\section{Dealing with missing data}

We contacted the trial authors of the original studies when further information was required. We performed analyses based on intention-to-treat (ITT), such that we assumed missing data for randomised participants to be treatment failures in this review. As this ITT analysis may underestimate the effect of the intervention, we performed both ITT and on-treatment analyses to explore the impact of missing data on the overall outcome. We presented the findings of these analyses in the Discussion section.

\section{Assessment of heterogeneity}

We assessed included trials for heterogeneity (which is a variation in study outcomes amongst the studies as further defined in Higgins 2011) through two successive steps to determine if they should be pooled with the rest of the included trials or reported in a systematic review.

1. Two review authors (KL, JP) independently analysed trials for their 'face-value' similarities, i.e. for clinical diversity (participants, interventions, and outcomes) and methodological diversity (study design and risk of bias). 
2. We subsequently assessed trials for statistical heterogeneity using the $\mathrm{Chi}^{2}$ test with a $\mathrm{P}$ value of less than 0.10 being statistically significant. We calculated the $1^{2}$ statistic as instructed in the Cochrane Handbook for Systematic Reviews of Interventions (Higgins 2011; RevMan 2014). If this was greater than $50 \%$, we considered the pooled trials to be significantly heterogeneous.

\section{Assessment of reporting biases}

Had a sufficient number of studies had been pooled (i.e. greater than 25), we planned to use a funnel plot to visually inspect the risk of publication bias, where more pronounced asymmetry of the funnel plot may be indicative of a substantial overestimation of the intervention effect (Higgins 2011; RevMan 2014).

\section{Data synthesis}

We synthesised the data as follows.

1. We used a fixed-effect model for binary or continuous data in the absence of statistical heterogeneity $(12<50 \%)$ according to the Cochrane Handbook for Systematic Reviews of Interventions (Higgins 2011; RevMan 2014).

2. We used a random-effects model for binary or continuous data in the presence of statistical heterogeneity $(12>50 \%)$ for pooling the trial data using the Mantel-Haenszel method according to the Cochrane Handbook for Systematic Reviews of Interventions (Higgins 2011; RevMan 2014). This model of analysis makes the assumption that the studies are not measuring for the same intervention effect, instead estimating for an overall intervention effect that is trending amongst the studies.

3. We also used the fixed-effect model to pool study data that reported events as rates according to the Cochrane Handbook for Systematic Reviews of Interventions; only fixed-effect metaanalysis methods are available in Review Manager 5 for ' $\mathrm{O}-\mathrm{E}$ and Variance' outcome (Higgins 2011; RevMan 2014).

\section{GRADE and 'Summary of findings' table}

We created a 'Summary of findings' table using the following outcomes: acute exacerbations, mortality, carriage levels, antibiotic prescriptions, hospital admissions, adverse events, and quality of life. We used the five GRADE considerations (study limitations, consistency of effect, imprecision, indirectness, and publication bias) to assess the quality of a body of evidence as it relates to the studies which contribute data to the meta-analyses for the prespecified outcomes (Atkins 2004). We used methods and recommendations described in Section 8.5 and Chapter 12 of the Cochrane Handbook for Systematic Reviews of Interventions (Higgins 2011), using GRADEpro GDT software (GRADEpro GDT 2014). We justified all decisions to down- or upgrade the quality of studies using footnotes, and we made comments to aid the reader's understanding of the review where necessary.

Outcomes that presented data as dichotomously, had their assumed risk calculated by taking the proportion of participants in the placebo group that encountered the event, and thus, the corresponding risk calculated by applying the relative effect to the assumed risk.

Outcomes that presented data as rates, had their assumed risk calculated by taking the average rate of events in the placebo group (measured in events per person per year), and thus, the corresponding risk calculated by applying the relative effect to the assumed risk. Refer to the Additional tables for the event rates for each of the studies included in the meta-analysis.

\section{Subgroup analysis and investigation of heterogeneity}

If sufficient data were available, we planned to explore specific subgroups for further analyses of treatment effect.

1. Comparison of continued-smoking versus ex-smoking populations.

2. Younger (< 65 years) versus older (65 years and older) participants.

\section{Sensitivity analysis}

If sufficient data were available, we planned to perform sensitivity analyses by:

1. examining how the addition of studies at high risk of bias to studies at low risk of bias impacted on the overall outcome to determine the effects of risk of bias; and

2. examining which studies contributed to heterogeneity and how this impacted on the overall outcome.

We used different methods of pooling, for example initially pooling all trials and then excluding one by one specific trials from the meta-analysis and comparing the results, whilst also comparing the use of a fixed-effect versus random-effects model for the pooling analysis. Otherwise, we entered trials one by one into the metaanalysis to assess the robustness of the pooled estimates.

\section{RES U L T S}

\section{Description of studies}

\section{Results of the search}

We obtained 199 records from our searches as described in Search methods for identification of studies. From the search result, we identified 10 randomised controlled trials (RCTs) that provided data pertinent to the NTHi oral vaccine in preventing acute exacerbations in chronic bronchitis and COPD (Figure 1). 
Figure 1. Inclusion of trials flow diagram.

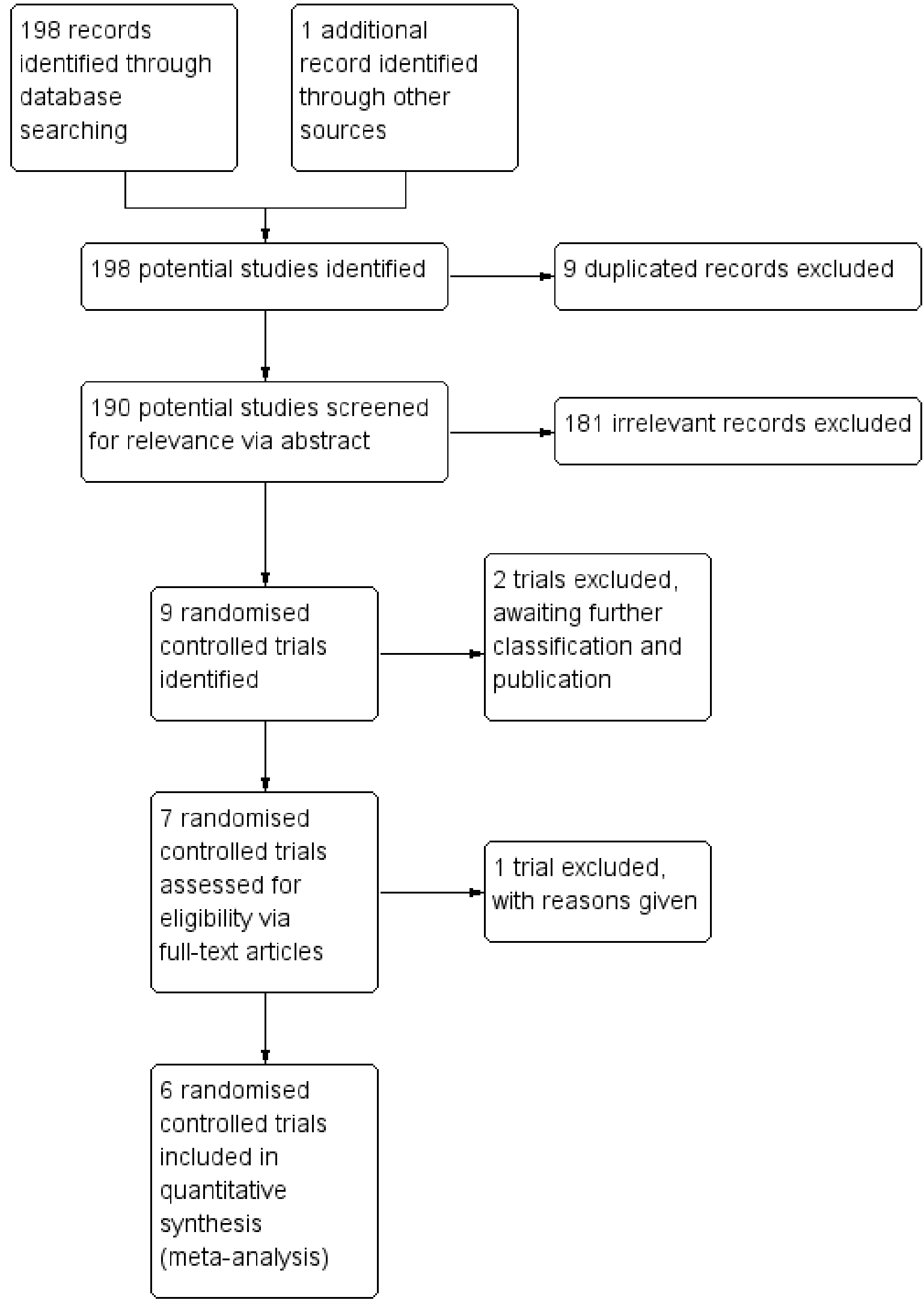




\section{Included studies}

We included six studies in this review (Clancy 1985; Clancy 1990; Clancy 2016; Lehmann 1991; Tandon 1991; Tandon 2010). We have summarised the main features of the included trials in the Characteristics of included studies table. We have summarised the key results of the included trials in the Summary of findings for the main comparison. We have described the methods here in greater detail, largely using direct excerpts of the original papers, as these demonstrate the strengths and weaknesses of the trials in the words of the original authors.

\section{Overview}

All six of the included studies were clinical placebo-controlled RCTs, five of which were double-blinded (Clancy 1985; Clancy 2016; Lehmann 1991; Tandon 1991; Tandon 2010), and one of which was single-blinded (Clancy 1990). They were conducted to test the efficacy of enteric-coated, killed preparations of $H$ influenzae in populations prone to recurrent acute exacerbations of chronic bronchitis or COPD. The vaccine preparation and immunisation regimen used in all trials consisted of at least three courses of formalin-killed $H$ influenzae in enteric-coated tablets taken at intervals (e.g. on days 0, 28, and 56). Each course generally consisted of two tablets taken after breakfast over three consecutive days. In all cases, the placebo groups took entericcoated tablets containing glucose.

The trials varied in duration from three to 12 months. Randomisation in the trials was achieved by having a pharmacist independently prepare treatment packages that contained either active or placebo tablets (Clancy 1990; Lehmann 1991; Tandon 1991). These packages were numbered and randomised before being distributed to the clinicians involved in the trials, where the pharmacist was responsible for disclosing the randomised codes at the conclusion of the trial.

The trials varied in population groups, with most trials including chronic bronchitis or COPD patients in Australia with mean ages between 40 and 80 years (Clancy 1985; Clancy 1990; Clancy 2016; Tandon 1991; Tandon 2010). Lehmann 1991 was conducted in chronic bronchitis or COPD patients in Papua New Guinea, with a mean age of 51 years.

Bacterial load was assessed by a standardised method across the six trials. Multiple cultures were performed on each person. In normal circumstances, the first culture following vaccination was taken at three months. Cultures were taken at regular threemonthly intervals and extra cultures taken during illness. The methods of obtaining samples and transporting material and culture methods generally followed a set protocol for adequate specimen handling and control. However, the lack of consistency and wide variety of measurement styles used amongst the studies to calculate and report carriage levels made analyses between studies difficult.

Measured outcomes in the trials varied but included bacterial load within the respiratory tract, the number and severity of acute exacerbations, and the usage of antibiotics. These outcomes were not always statistically useful.

Corticosteroids were administered at a similar rate in both active and placebo groups. Antibiotics were prescribed in both arms of the trial according to standard respiratory medicine clinical criteria at the time of the respective trials. Such criteria included increase in volume and purulence of sputum, usually with increased breathlessness and sometimes fever.

Clancy 1985 was carried out and published by Clancy in 1985 and 1987 and is the oldest trial relevant to this review. It is a double-blind, placebo-controlled RCT conducted in New South Wales (Australia) over a period of three months in the winter of 1983. The mean age was 65.5 years in the treatment group and 64.7 years in the placebo group. The focus of the study was the immunogenicity of the $H$ influenzae oral vaccine and the clinical impact on people with airways damaged by COPD who suffered recurrent episodes of acute bronchitis. Fifty people with COPD (not taking corticosteroids or immunosuppressants) were recruited from the chest clinic of the Royal Newcastle Hospital and were given a three-day course of tablets (two daily) at 0,28 , and 56 days. Both placebo and NTHi vaccine were enteric-coated. Clancy 1985 utilised two placebo arms in their trial: the first group was given enteric-coated glucose tablets, and the second was given sodium tauroglycocholate. We have used the results from the first placebo group as this is a standard, widely used placebo, rather than the sodium tauroglycocholate group, as this placebo may have contributed some therapeutic effect. Participants were assessed by a chest physician, with lung function (spirometry), throat cultures, and saliva samples collected at baseline, 28,56 , and 84 days. The characteristics of participants entered into the trial demonstrated a very representative population: older adults (mean age 65 years), majority male (M:F 4.5:1), majority smokers (86\%). $H$ influenzae was isolated from $69 \%$ of sputum samples collected during acute bronchitis episodes in this population. Clancy 1985 concluded that the NTHi vaccine resulted in over $90 \%$ protection against acute exacerbations compared to the placebo group. This was not the case at follow-up a year later, at which point there was no significant reduction in incidence of $H$ influenzae carriage, that is no clear correlation between clinical protection from acute exacerbations and either carriage of $H$ influenzae or the level of antibody to $H$ influenzae antigen in saliva was evident. It was also noted that the protection provided by the vaccine did not extend to the subsequent winter, which is consistent with the knowledge that mucosal immunity is less durable than systemic immunity.

Clancy 1990 was a double-blind RCT conducted in Australia over a six-month period. There were a total of 37 participants with each group having similar baseline characteristics. The population in this study had a mean age of $65.5+/-2.9$ and was recruited from a chest clinic in Newcastle. Episodes were defined by an increase in purulence and volume of sputum with associated fever, cough, shortness of breath, and antibiotic therapy. Each participant was assessed by a chest physician, completed a respiratory questionnaire (American Thoracic Society Division of Lung Disease questionnaire (ATS-DLD-78)), and had sputum and mixed saliva samples taken and lung function via spirometry. Each group received three courses of oral tablets for three consecutive days at 0,28 , and 56 days. One group received the active preparation containing $H$ influenzae vaccine, while the other group received a glucose-containing placebo preparation. There was a significant reduction in the number of episodes of acute wheezy bronchitis in the treated group with a $\mathrm{P}$ value of 0.02 . There was a significant reduction $(41 \%)$ in the total number of acute infections in the treatment group compared to the placebo group but no significant change when acute infections were considered in an individual from either group. This study had other modes of measuring

Haemophilus influenzae oral vaccination for preventing acute exacerbations of chronic bronchitis and chronic obstructive pulmonary 
severity, such as the number of participants reporting infections and the number of infections prescribed antibiotics, and all results supported the treatment group. There was no significant difference noted in the side effect profile in either group.

Clancy 2016 was a double-blind, placebo-controlled, prospective study conducted for nine months over the Australian winter of 2011. The study included 320 people with moderate-severe COPD with $\mathrm{FEV}_{1}$ less than $60 \%$, requiring oral systemic corticosteroid therapy or admission into hospital, recruited from 21 sites across Australia; the mean age of participants was 71.2 years in the treatment arm and 67.9 years in the placebo arm. Participants in the intervention group were given two $\mathrm{HI}-164$ oral vaccine entericcoated tablets per day, each of which contained $45 \mathrm{mg}$ of the formalin-inactivated NTHi (HI-164) active vaccine; participants in the placebo group received a glucose substitute. Study outcomes assessed the number of exacerbations (according to the St George's Respiratory Questionnaire for COPD), carriage levels (from cultured sputum samples), hospitalisations, and antibiotic/steroid prescriptions (based on medical records). The aim of this study was to extend the database from earlier and smaller studies showing that maximum protection occurred in those with most severe disease, with the most sensitive indicator being a reduction in exacerbations requiring corticosteroid therapy or hospital admission, or both. Clancy 2016 provides evidence that the agerelated vaccine benefits in COPD noted with parenteral vaccines also apply to oral vaccines that enhance mucosal immunity within the bronchus. The results were only minutely significant in circumstances of low exposure to NTHi and only amongst a subgroup of younger participants (aged under 65), given more responsive immune systems and less established airway disease. The results were otherwise not significant for those older than 65 years of age.

Lehmann 1991 was a prospective, double-blind RCT, conducted through the Pneumonia Research Programme in Papua New Guinea. As a result, the demographic characteristics differed significantly to those found in high-income communities. Potential participants were identified by nomination from town residents and villagers and were then followed up by a standard questionnaire, which identified people suffering from chronic lung disease. Participants who matched the eligibility criteria were examined with lung function tests and spirometry at time of entry into the trial. Randomisation and blinding of medication and placebo were done by the pharmacy department at the Royal Newcastle Hospital, New South Wales, Australia; the placebo and active vaccine looked identical, and the randomisation code was held by Auspharm International Ltd until the completion of the trial. Both groups were similar at baseline following allocation. Doctors and nurses oversaw the administration of medication to maintain compliance during the 12-month follow-up period. Eight participants in the vaccine group and three in the placebo group were lost to follow-up, with three deaths in the vaccine group and one death in the placebo group. The trial does not mention any ITT analysis for these participants, rather stating "permanent exit from the study were excluded from the calculation", potentially creating attrition bias. The trial concludes that for the population of the highlands of Papua New Guinea, the vaccine protected against episodes of acute bronchitis, but not against more severe forms of acute lower respiratory tract infection. A limitation of the study was the need for a larger population group to ensure greater statistical

Haemophilus influenzae oral vaccination for preventing acute exacerbations of chronic bronchitis and chronic obstructive pulmonary disease (Review)

Copyright @ 2017 The Cochrane Collaboration. Published by John Wiley \& Sons, Ltd. power to help determine the extent of protection oral $H$ influenzae vaccine could provide.

Tandon 1991 was a double-blind RCT, conducted in 1988 at the repatriation hospital in Western Australia. This study recruited 64 participants with chronic bronchitis and a history of recurrent respiratory tract infections to learn whether oral NTHi immunisation is effective in this patient population. Participants were divided randomly into placebo (mean age 71.1 years) and vaccine (mean age 73.1 years) groups. All participants followed the same treatment regimen consisting of three courses of the tablets on days 0,28 , and 56 . Study outcomes were acute infective episodes, number of antibiotic prescriptions, and colonisation with $H$ influenzae, monitored through the following strategies: primary care physician for diagnosing acute infective episodes, sputum sample, and visual analogue scale. For all of these variables, better outcomes were demonstrated in the vaccine group. Previous studies have demonstrated that $H$ influenzae is the main constituent in bacterial colonisation of the bronchus, and therefore vaccinating against it would reduce the incidence of acute exacerbations, which is consistent with the results of this study.

Tandon 2010 was a multicentre, double-blind, placebo-controlled trial conducted at four sites around Australia. The study tested the efficacy of $\mathrm{HI}-1640 \mathrm{O}$ in reducing the number and severity of acute exacerbations in people with severe COPD. Acute exacerbations were defined by an increase in volume and purulence of sputum. Each participant was administered the same regimen (two tablets daily for three consecutive days) with courses repeated at day 28 and 56. All tablets were identical-looking, enteric-coated capsules that contained either vaccine $(\mathrm{N}=18$ ) or placebo ( $\mathrm{N}$ $=20$ ). Participants were followed up every four weeks via a respiratory questionnaire, sputum and nasopharyngeal swabs were collected to monitor bacterial colonisation, and blood samples were collected to monitor antibodies. The primary variables were the number and duration of exacerbations and the number of antibiotic courses prescribed. Baseline demographic characteristics, such as mean age (vaccine 69.5, placebo 67.5) were very similar, demonstrating effective randomisation. However, the exact method of randomisation was not disclosed. Four of the six authors of this study disclosed that they had received funding from Hunter Immunology Ltd. The authors concluded that the vaccine was safe and had a significant efficacy in participants with severe COPD. Benefits were noted with respect to a reduction in the severity of episodes (duration of episodes; 14.3 vaccine group and 22.7 placebo, $P<0.01$ ), which required less antibiotic therapy (event rate; 0.83 vaccine and 1.15 placebo, $\mathrm{P}<0.05$ ) and fewer admissions to hospital (three in the vaccine group compared to 12 in the placebo group, $\mathrm{P}<0.05)$. However, a reduction in the incidence of episodes did not reach significance, possibly because the study was significantly underpowered.

\section{Excluded studies}

We excluded one study because it did not meet our inclusion criteria (Clancy 2010). As noted in Characteristics of excluded studies, the participant population included smokers who did not have formally diagnosed COPD or chronic bronchitis, and outcome measures were limited to physiological markers that did not include the clinical outcomes defined in this review's protocol.

Two studies are cited only in trial registries and are pending formal publication of the raw trial data by the 
investigators (ACTRN12606000074594; ACTRN12606000076572). The main features of these unpublished trials can be found in Characteristics of studies awaiting classification. These trials will potentially be incorporated into future updates of this review.

\section{Risk of bias in included studies}

A summary of the 'Risk of bias' assessment is detailed in the Characteristics of included studies table.

\section{Allocation}

The random sequence generation in the studies was generally determined to be poor, with $50 \%$ of the studies graded as either at high or unclear risk of bias because they did not provide any information regarding the random sequence generation and subsequent allocation process (Clancy 1985; Clancy 2016; Tandon 2010). We considered the remaining studies to have a low risk of bias given that it was reported that a third party conducted randomisation and that the allocation codes were kept confidential until the end of the trial (Clancy 1990; Lehmann 1991; Tandon 1991).

The allocation concealment in the selected studies was generally poor, with $67 \%$ of the studies categorised as either at unclear or high risk of bias (Clancy 1985; Clancy 1990; Clancy 2016; Tandon 2010). Only two studies demonstrated a low risk of bias, where the handling and distribution of the treatment packages were carried out independently by the pharmacist, who employed an appropriate randomisation chart and safely kept the package trial code associated with the participants (Lehmann 1991; Tandon 1991).

\section{Blinding}

All studies performed suitable blinding except for one, which we deemed to be at high risk of bias because it did not blind the commercially available polybacterial tablets (Clancy 1990); for this reason, the study was subsequently conducted as a single-blind trial (participants blinded). All of the remaining studies reported using double-blinded identical enteric-coated tablets for both intervention and placebo arms of the trial.

\section{Incomplete outcome data}

Five of the six included studies accounted for and provided sufficient information regarding the follow-up of participants who had dropped out of the trials (Clancy 1985; Clancy 1990; Clancy 2016; Tandon 1991; Tandon 2010). Lehmann 1991 made no mention of ITT analysis and reported a substantial loss to follow-up (eight participants from the vaccine group and three from the placebo group), especially considering the small group size.

\section{Selective reporting}

We found no selective reporting in any of the studies.

\section{Other potential sources of bias}

We identified no other potential sources of bias in any of the studies.

\section{Effects of interventions}

See: Summary of findings for the main comparison Haemophilus influenzae oral vaccination for prevention of acute exacerbations of chronic bronchitis and chronic obstructive pulmonary disease (COPD)

\section{Primary outcomes}

\section{Incidence of acute exacerbations of chronic bronchitis or chronic obstructive pulmonary disease (COPD)}

Six trials evaluating 557 participants assessed the effectiveness of non-typeable Haemophilus influenzae (NTHi) oral vaccination on the frequency of acute exacerbations in people with advanced lung disease (Figure 2; Table 1). The meta-analysis concluded that there was a small, non-significant $2.048 \%$ decrease in exacerbations in the vaccinated group when compared to the placebo group (RR $0.79,95 \% \mathrm{Cl} 0.57$ to $1.10 ; \mathrm{P}=0.16$ ) (Analysis 1.1 ).

Figure 2. Forest plot of comparison: 1 Primary outcomes, outcome: 1.1 Exacerbations (number of exacerbations/ person/year). Refer to Table 1 for Overall rate estimates of acute exacerbations across included studies.

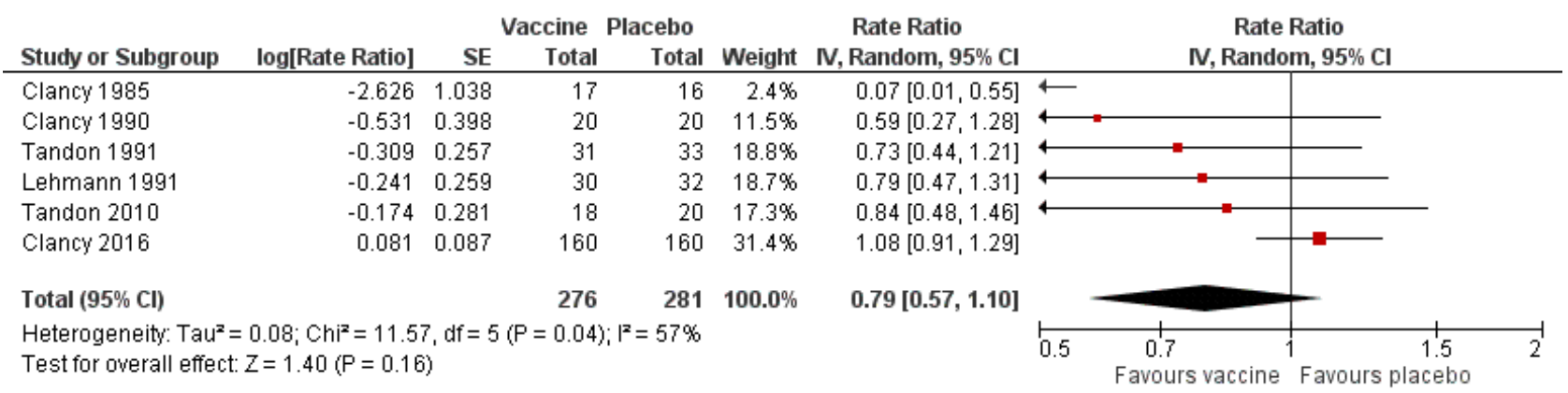

Despite all trials having almost identical primary objectives, there were considerable discrepancies in the manner in which the primary outcomes were reported. For example, Clancy 1985 reported overall number of infections, whereas Tandon 2010 reported the number of infections per participant. In order to allow meaningful comparisons between studies, we converted all data into a rate of exacerbations (number of exacerbations per participant per year).
Of the six studies incorporated into the review, only one demonstrated an effect that favoured the vaccination group (Clancy 1985). Clancy 1985 was a small trial that enrolled 33 participants. The data showed a very significant positive effect in favour of the vaccine group, recording only one event compared to 13 in the placebo group, which was statistically significant (RR $0.07,95 \% \mathrm{Cl} 0.01$ to 0.55 ), despite the very large $\mathrm{Cl}$. However, subgroup analysis demonstrated that removing this study from the 
pool had no bearing on the overall meta-analysis outcome, as its small population meant this study's weighting was very small.

Five studies, with a total of 504 participants, did not show a significant increase in the number of exacerbations (Clancy 1990; Clancy 2016; Lehmann 1991; Tandon 1991; Tandon 2010). As a result, their combined contribution to this meta-analysis weighting was $99.5 \%$.

Clancy 2016 was the largest trial, comprising 320 participants and receiving over $70 \%$ of the meta-analysis weighting. It showed a non-significant $8 \%$ increase in the number of exacerbations in the placebo group (RR 1.08, 95\% Cl 0.91 to 1.29). Clancy 2016 reported 249 events in the vaccine group compared with 270 in the placebo group.

There was a moderate degree of heterogeneity in this meta-analysis $(12=57 \%, P=0.04)$, hence a random-effects model of analysis was used. The study contributing most to this effect was Clancy 1985. Removal of Clancy 1985 dramatically reduces the heterogeneity (I2 $=24 \%, P=0.26)$, but did not change the overall result.

\section{Mortality}

None of the trials formally assessed mortality as an outcome. However, five trials reported death of trial participants (Figure 3) (Clancy 1985; Clancy 2016; Lehmann 1991; Tandon 1991; Tandon 2010). Of these deaths, none were attributed to the vaccine and most were considered the natural endpoint of the participants' respiratory disease or other unrelated chronic disease. There was a greater incidence of mortality in the placebo group. However, this result was not statistically significant (OR $1.62,95 \% \mathrm{Cl} 0.63$ to 4.12; $\mathrm{P}=0.31)$, with a low amount of heterogeneity between results $\left(\mathrm{I}^{2}=\right.$ $9 \%, \mathrm{P}=0.36$ ) (Analysis 1.2).

Figure 3. Forest plot of comparison: 1 Primary outcomes, outcome: 1.2 Mortality (deaths during trial period).

\begin{tabular}{|c|c|c|c|c|c|c|c|c|c|c|}
\hline \multirow[b]{2}{*}{ Study or Subgroup } & \multicolumn{2}{|c|}{ Vaccine } & \multicolumn{2}{|c|}{ Placebo } & \multirow[b]{2}{*}{ Weight } & \multirow{2}{*}{$\begin{array}{c}\text { Odds Ratio } \\
\text { M-H, Fixed, 95\% Cl }\end{array}$} & \multirow{2}{*}{\multicolumn{4}{|c|}{$\begin{array}{c}\text { Odds Ratio } \\
\text { M-H, Fixed, 95\% Cl }\end{array}$}} \\
\hline & Events & Total & Events & Total & & & & & & \\
\hline Clancy 1985 & 0 & 17 & 2 & 17 & $34.4 \%$ & $0.18[0.01,3.98]$ & & - & & \\
\hline Clancy 2016 & 4 & 160 & 2 & 160 & $27.6 \%$ & $2.03[0.37,11.22]$ & & & - & \\
\hline Lehmann 1991 & 3 & 30 & 1 & 32 & $12.3 \%$ & $3.44[0.34,35.09]$ & & & & \\
\hline Tandon 1991 & 3 & 31 & 0 & 33 & $6.1 \%$ & $8.23[0.41,166.09]$ & & & & \\
\hline Tandon 2010 & 0 & 18 & 1 & 20 & $19.6 \%$ & $0.35[0.01,9.18]$ & & & & \\
\hline Total $(95 \% \mathrm{Cl})$ & & 256 & & 262 & $100.0 \%$ & $1.62[0.63,4.12]$ & & & & \\
\hline Total events & 10 & & 6 & & & & & & & \\
\hline $\begin{array}{l}\text { Heterogeneity: } \mathrm{Chi}^{2} \\
\text { Test for overall effec }\end{array}$ & $\begin{array}{l}4.38, d f= \\
Z=1.00\end{array}$ & $\begin{array}{l}4(P= \\
P=0.3\end{array}$ & $\begin{array}{l}0.36) ; 1^{2}= \\
\text { 1) }\end{array}$ & $=9 \%$ & & & 001 & $\begin{array}{c}0.1 \\
\text { s pla }\end{array}$ & ${ }^{1} \frac{10}{10}$ & 1000 \\
\hline
\end{tabular}

\section{Secondary outcomes}

\section{Carriage level of NTHi in the respiratory tract}

All six RCTs attempted analysis of carriage levels of $H$ influenzae in participants. We could not perform a meta-analysis as a myriad of different techniques were used to measure carriage levels objectively (throat swabs, sputum samples and culture), and carriage rates were measured at different intervals. Three trials failed to find a significant difference between carriage levels (Clancy 1985; Clancy 1990; Tandon 1991). Two studies showed a significant decrease in carriage rates in the vaccine group (Lehmann 1991; Tandon 2010). In one study, carriage levels were measured, but sputum samples could only be obtained at $36 \%$ of planned visits, of which $11 \%$ grew a respiratory pathogen; these numbers were too small to determine any significant effect following vaccination (Clancy 2016).

Lehmann 1991 showed the mean concentrations of $H$ influenzae carriage levels during acute exacerbations to be higher in the vaccine group (8.91 × $10^{6}$ colony-forming units (cfu)) when compared against the placebo $\left(1.55 \times 10^{6} \mathrm{cfu}\right)$. However, this only equated to a $5 \%$ difference between the vaccinated and placebo arms when counting individual specimens, whereby $91 \%$ of the vaccinated and $86 \%$ of the placebo collected specimens successfully grew $\mathrm{H}$ influenzae colonisations during the trial period.

Tandon 2010 demonstrated that there was a significant $(P<$ 0.05 ) two-fold difference between the placebo and active arms in overall positive cultures (65 positive cultures in the placebo group compared to 33 in the vaccine group). However, the percentage of validated sputum samples was $50 \%$ and $48 \%$ for placebo and active groups, respectively. $H$ influenzae accounted for only $51 \%$ and $33 \%$ of positive cultures in the placebo and vaccinated groups, respectively.

There was a trend for studies to report a transient decline in $\mathrm{H}$ influenzae carriage levels. However, this had always returned to baseline by the end of the study time frame. Tandon 1991 noted a transient drop in carriage levels to $12 \%$ at 14 weeks in the active group, which then reverted back to $25 \%$ at 24 weeks. This is a $4 \%$ drop over 24 weeks. The placebo group noted a small $2 \%$ drop over the 24-week study period. Furthermore, in Clancy $1985 \mathrm{H}$ influenzae was isolated from throat swabs from $70 \%$ of the placebo group compared with $53 \%$ of the vaccination group at the end of a fourweek period. Carriage rates at 12 weeks declined to $50 \%$ in the placebo group and $23 \%$ in the vaccine group.

\section{Numbers of prescriptions for antibiotics and corticosteroids in the trial and follow-up periods (including hospital admissions) as an indication of severity of acute exacerbations}

Four studies, evaluating 462 participants, assessed the effect of NTHi oral vaccination on the number of antibiotic prescriptions in people with chronic bronchitis (Clancy 1990; Clancy 2016; Tandon 1991; Tandon 2010) (Figure 4; Table 2).

Haemophilus influenzae oral vaccination for preventing acute exacerbations of chronic bronchitis and chronic obstructive pulmonary 
Figure 4. Forest plot of comparison: 2 Secondary outcomes, outcome: 2.1 Prescriptions (number of courses/person/ year). Refer to Table 2 for Overall rate estimates of antibiotic prescriptions across included studies.

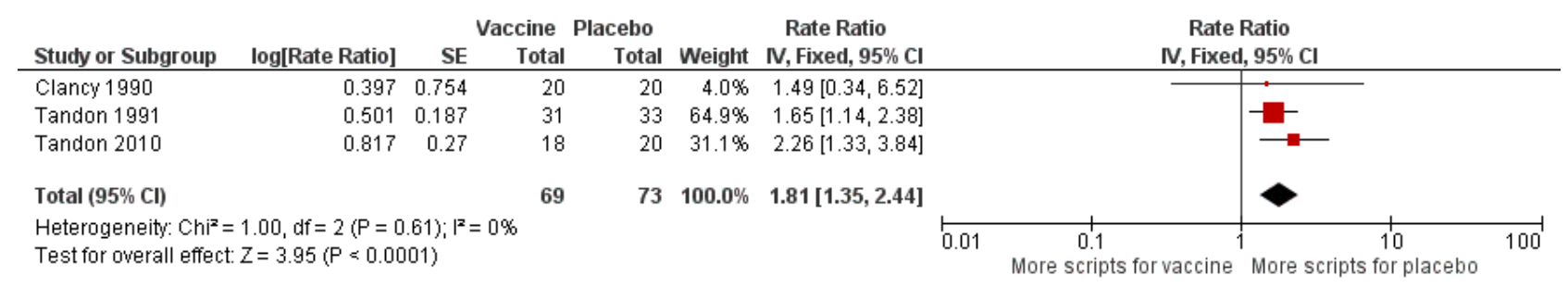

There were considerable discrepancies amongst studies in the way antibiotic prescriptions were objectively measured. We attempted to convert the reported data into a rate (number of courses/person/ year) in order to achieve an objective comparison. However, this was not possible with data from the Clancy 2016 trial, which unlike the other studies only reported mean antibiotic use in days. As a result, we could pool only three studies in meta-analysis. Two studies did not report any information on antibiotic usage in this population (Clancy 1985; Lehmann 1991).

The three studies in the meta-analysis included 143 participants (Clancy 1990; Tandon 1991; Tandon 2010). Two of these studies produced data that favoured the vaccination group (Tandon 1991; Tandon 2010), whereas the Clancy 1990 data did not reach significance. The overall effect was a statistically non-significant $81 \%$ increase in use of antibiotic courses per person in the placebo group when compared against the vaccinated group (RR 1.81, 95\% $\mathrm{Cl} 1.35$ to $2.44 ; \mathrm{P}<0.001$; with a $\mathrm{RR}>1.0$ indicating greater antibiotic usage in the placebo group) (Analysis 2.1). The majority of the weighting could be attributed to Tandon 1991 and Tandon 2010: $64.9 \%$ and $31.1 \%$, respectively, and both favoured the vaccination group.

Tandon 1991 showed a significant decrease in antibiotic prescriptions ( 45 in the active group and 79 in the placebo group). Tandon 2010 showed a significant $56 \%$ reduction in the number of prescribed antibiotics following active treatment $(P<0.05)$. Clancy 1990 reported a reduction in the number of antibiotics in the active group compared to the placebo group, but this failed to reach statistical significance.

The Clancy 2016 trial is by far the largest study in this review (three times the combined size of the other three trials included in this outcome), contributing 320 of the 462 participants. Clancy reported that there was no significant difference between the two groups in terms of antibiotic usage (active group 13.5 days per episode with a range of 0 to 289; placebo group 14 days per episode with a range of 1 to 122). Given the wide and varied protocols for antibiotic administration, it was impossible to translate this into course/person/year as with the other trials.

Corticosteroid prescriptions were not strictly studied as an outcome in the studies, and thus we did not meta-analyse these; nonetheless, usage was noted in participants in at least two studies (Clancy 2016; Tandon 2010), and we have considered their indications and study findings for their use in the Summary of main results.

Hospitalisation data amongst the studies were limited, with only two studies reporting hospitalisations of their participants (Clancy 2016; Tandon 2010). The two studies presented data different units of measurement therefore not allowing the 2 studies to be metaanalysed together; Clancy 2016 presented their data has a rate ratio, whereas Tandon 2010 presented data dichotomously. We have considered their indications and study findings for their use in the Summary of main results.

\section{Any associated adverse side effects from the NTHi vaccination, measurable from symptomology and participant reports}

All studies except Clancy 1985 reported adverse events, although none of the trials studied this as an outcome. In total, 142 adverse events were reported; of these, 72 occurred in the active group and 68 occurred in the placebo group (Analysis 2.2; Figure 5; Table 3). Reported adverse effects were largely gastrointestinal in nature, although increased dyspnoea or general malaise were also commonly reported; none of these were found to be directly attributable to the oral vaccine.

\section{Figure 5. Forest plot of comparison: 2 Secondary outcomes, outcome: 2.3 Adverse events (number of adverse} events/person/year). Refer to Table 3 for Overall rate estimates of adverse events across included studies.

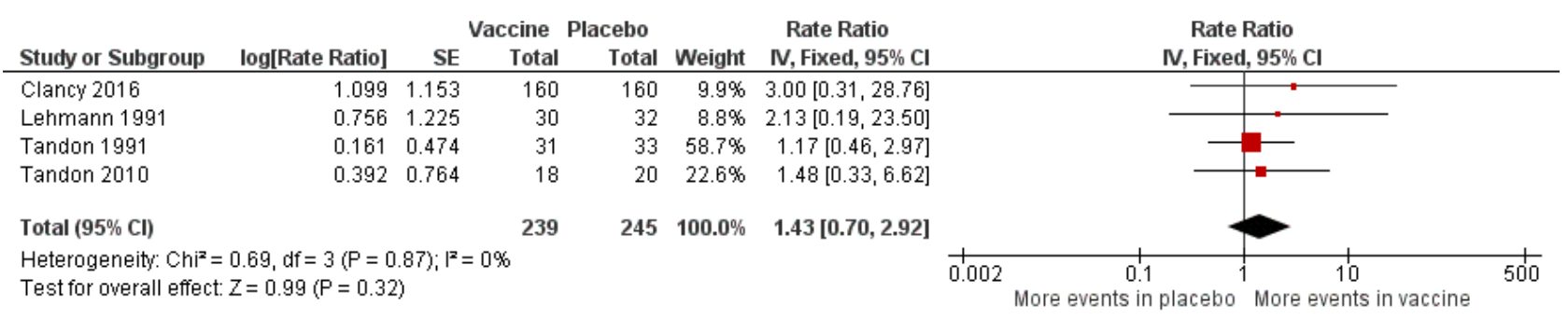

Haemophilus influenzae oral vaccination for preventing acute exacerbations of chronic bronchitis and chronic obstructive pulmonary 
Clancy 2016 reported that adverse event rates were similar in both groups $33.5 \%$ in the placebo group compared with $38.5 \%$ in the vaccinated group), although the actual number of events was not provided in the original publication. Further data provided by the study authors showed that one participant in the active group had an adverse event compared with three participants in the placebo group.

\section{Quality of life}

Two studies reported quality of life measurements, however as they used different assessment scales they were not comparable and we therefore did not meta-analyse them (Clancy 2016; Tandon 1991). Tandon 1991 reported a global assessment for general well-being using a visual analogue scale, which showed at 24 weeks a median score of 5.0 in the vaccine group compared to 2.5 in the placebo group $(P=0.09)$. Clancy 2016 measured quality of life using the St George's Respiratory Questionnaire for COPD for those under 65 years old, reporting a significant difference in symptom scores in favour of the vaccine group at three months $(P=0.02)$ and six months $(P=0.01)$. Data were not provided for older age groups.

\section{DISCUSSION}

\section{Summary of main results}

\section{Incidence of acute exacerbations of chronic bronchitis or COPD}

In this review we evaluated the effectiveness of a NTHi oral vaccination in reducing acute exacerbations in people with chronic bronchitis/COPD. The results indicated that the vaccination has no significant impact in reducing the number of exacerbations. Only one study was able to demonstrate a statistically significant effect, which favoured vaccination (Clancy 1985). This was the smallest study and contributed significant heterogeneity to the metaanalysis. When we removed Clancy 1985 from the meta-analysis, we found no significant difference for the primary outcome. All other studies showed no significant treatment effect.

Among the studies included in the review, there were considerable differences in the methodology and intervals at which measurements were recorded. The main outcome (acute exacerbations) was measured differently across the six studies, providing a challenge for comparison. For example, Clancy 1985 records results as a proportion, whereas Lehmann 1991 utilises rates. There were also notable discrepancies in the study time periods, with Clancy 1985 reporting data at three months and Clancy 1990 providing data up to six months. Data recorded at nine to 12 months could only be elicited from two trials. As a result, we converted all data into rates so that studies could be objectively compared, irrespective of their varying follow-up protocols.

Other differences amongst the trials included variation in population (Lehmann 1991 was conducted in Papua New Guinea), the use of subjective measurements such as respiratory questionnaires to measure exacerbations, and seasonal variations. These may have contributed to the marked heterogeneity $(12=57 \%$, $P=0.04)$ identified in the meta-analysis.

Only one study was large enough to be able to conduct subgroup analysis stratified by age (Clancy 2016). A subgroup analysis excluding all participants older than 65 years concluded that the mean number of exacerbations was significantly higher in the placebo group (56) when compared to the vaccinated group (34) (P
$<0.001$ ). There was also a statistically significant difference in the days to first exacerbation ( 87 days in the placebo group compared to 111 days in the vaccine group). Although the data at this stage were limited, these results suggest the use of the NTHi vaccination in a younger population, especially considering that there was no difference in mortality or adverse events in the two groups. The apparently greater efficacy of the vaccine seen in those less than 65 years old may be a reflection of a less severe burden of disease; younger patients generally have a shorter smoking history, fewer exacerbations, and fewer comorbidities. Further studies need to be conducted in younger patients and considering the varying severity of COPD to identify whether there is a significant treatment effect in this population.

\section{Mortality}

We found mortality rates overall to be higher in the placebo group. However, these results were not statistically significant and are unconvincing. There was no apparent association with treatment effect, and it is unclear whether the administration of the NTHi vaccine contributed to mortality.

Other patient factors were suggested to contribute to mortality in some trials, such as long-standing cirrhosis or a ruptured aneurysm reported in Tandon 1991 and Lehmann 1991. These comorbidities would have a significant effect on the mortality outcome given the small participant numbers.

Two trials reported the primary cause of death as a terminal respiratory infection (Lehmann 1991; Tandon 1991), with other studies reporting cause of death to be non-respiratory. Whilst it is understood that the most common cause of death in COPD patients is respiratory failure, it was not clearly demonstrated in this meta-analysis, which was likely due to inconsistent and insufficient reporting in the studies.

\section{Carriage level of NTHi in the respiratory tract}

All six trials measured sputum carriage levels of $H$ influenzae; these were obtained routinely and during acute exacerbations, although the methods of reporting and intervals at which routine samples were taken varied. This limited the extent to which these results could be compared.

A significant difference in the carriage rates was not consistently found between the placebo and vaccine groups in every trial. No significant difference over time in routine carriage rates was found between the groups in Clancy 1985, Lehmann 1991, and Tandon 1991. The largest of the studies obtained samples at only $36 \%$ of visits, and of these, a respiratory pathogen was isolated in only $11 \%$ (Clancy 2016). The sputum carriage levels were too small to determine any significant effect following vaccination.

In the majority of trials, $H$ influenzae was noted to play a prominent role during infective exacerbations. In Clancy 1985, $H$ influenzae was isolated from $69 \%$ of sputum samples collected during acute exacerbations, and from $33 \%$ and $44 \%$ in the placebo and vaccine groups, respectively in Clancy 1990 (this difference was not significant). Lehmann 1991 and Tandon 2010 did not discuss the bacterial carriage specifically during acute exacerbations. It is notable that Tandon 1991 found that the numbers of acute infective exacerbations were higher $(P=0.011)$ in participants in the vaccine group from whose sputum $H$ influenzae was isolated either before or during an acute episode. 
Clancy 2016 noted that of the sputum samples that grew a respiratory pathogen, $H$ influenzae played a role, but not a prominent one, accounting for only $6 \% ; 6.2 \%$ grew $S$ pneumoniae, 7.5\% Moraxella catarrhalis, and 6.0\% P aeruginosa. Clancy 1990 noted that during the six-month trial, the proportion of $H$ parainfluenzae infections was between $57 \%$ and $89 \%$ greater than the proportion of $H$ influenzae infections during the same time period across both groups. This poses the question of the clinical impact of treating $H$ influenzae as prophylaxis, as the background carriage rates may reflect the rates in acute exacerbation. The remaining four studies of this meta-analysis did not report whether other pathogens were cultured alongside $H$ influenzae; it is worthwhile to consider that acute (infective) exacerbations of COPD may be in part due to a host of multiple organisms rather than a single isolate.

The population studied in the Papua New Guinea study raises concerns about the potential applicability of the results to the COPD patient in high-income countries (Lehmann 1991). Asymptomatic background carriage rates were high: $57 \%$ of routine sputum samples isolated $H$ influenzae $(37 \%$ isolated S pneumoniae and $11 \%$ demonstrated $H$ parainfluenzae). There were also some significant methodological problems in this study, with 53 out of 362 samples needing to be excluded due to betel nut consumption or epithelial contamination.

\section{Numbers of prescriptions for antibiotics and corticosteroids in the trial}

Antibiotics were prescribed in four out of the six clinical trials (Clancy 1990; Clancy 2016; Tandon 1991; Tandon 2010), but this was not necessarily an effective outcome measure that correlated with disease progression or severity. Given the high variability and lack of consistency concerning antibiotic course administration and measurements, we could not perform a truly uniform assessment and comparison amongst the trials. Whilst the three studies pooled for quantitative analysis appeared to indicate slightly more prescriptions having been issued to participants in the placebo group (RR 1.81; 95\% Cl 1.35 to 2.44; $\mathrm{P}<0.001$ ) (Clancy 1990; Tandon 1991; Tandon 2010), this conclusion remains unconvincing. There was also no reported follow-up regarding what effect antibiotics had on participants (e.g. if there was resolution of symptoms or reduction in carriage levels).

The application of current therapeutic guidelines in the trials was similarly questionable, with the intentions and protocols for prescribing antibiotics largely unclear and not reported in their methods. It is understood that at least half of patients with chronic bronchitis and COPD are persistently colonised with $\mathrm{H}$ influenzae, $S$ pneumonia, or M catarrhalis (Lehmann 1991), hence a positive sputum culture that is not necessarily indicative of an acute infection and subsequent antibiotic prescription (in Tandon 2010, $48 \%$ in the vaccinated group and $50 \%$ in the placebo group had a validated positive sputum culture). Normally in exacerbations of COPD, sputum cultures would only be done if there was a failure of response to treatment or if the patient had repeated bacterial exacerbations within several months. Nonetheless, these organisms may be responsible for more severe exacerbations, for which antibiotics have been shown to be of benefit. The aim of treatment with antibiotics in acute exacerbations should be to alleviate symptoms and reduce the volume of sputum rather than total elimination of colonising organisms.

Haemophilus influenzae oral vaccination for preventing acute exacerbations of chronic bronchitis and chronic obstructive pulmonary disease (Review)

Copyright (c) 2017 The Cochrane Collaboration. Published by John Wiley \& Sons, Ltd.
None of the trials specified the class of antibiotic therapy used or explore sensitivities. This is important given that currently only amoxicillin and doxycycline regimens have been shown to be superior over other antibiotic classes such as macrolides, which fail to suppress H influenzae (Longo 2011).

Two trials measured the addition of corticosteroid use as an outcome (Clancy 2016; Tandon 2010). Clancy 2016 reported a median duration of five treatment days (minimum 0 , maximum 313 ) in the vaccine group and 10 days (minimum 0, maximum 306) in the placebo group. Tandon 2010 reported a total $56 \%$ reduction in the proportion with acute exacerbations with corticosteroid treatment across both vaccine and placebo arms of their trial; further analysis by the authors to see if it reduced subsequent recurrent exacerbations showed that there was a $33 \%$ reduction in the vaccine group compared to a $55 \%$ reduction in the placebo group, with an average of about $40 \%$ reduction for recurrent exacerbations.

Even though two studies reported the use of corticosteroids for the treatment of acute exacerbations, this does not preclude participants from receiving corticosteroids prior to and during the studies. Many of the participants were admitted to hospital during the study period and were likely to have received a short course of systemic corticosteroids (in Clancy 2016 and Tandon 2010 , a total of 83 participants in the vaccinated groups and 56 in the placebo groups). Short (not extended) courses of oral prednis(ol)one or intravenous hydrocortisone have been shown to shorten the duration of hospital admission and hasten return to previous lung function and stable symptom control and are routinely used for severe exacerbations of COPD (Longo 2011).

\section{Hospitalisations}

Two studies reported hospitalisations (Clancy 2016; Tandon 2010). Information in the studies regarding participant hospitalisations was limited and in different units of measurement therefore not allowing the 2 studies to be meta-analysed together; Clancy 2016 presented their data has a rate ratio, whereas Tandon 2010 presented data dichotomously. Further consistent data parameters, such as length of hospital stay and intensive care versus general ward admission, would have been necessary for a more complete analysis.

In the Tandon 2010 study, admissions to hospital were high in the placebo group, with 11 admissions compared to one admission in the vaccination group. This demonstrates that the chance of hospital admission for those receiving the NTHi vaccine was reduced by $90 \%(P=0.05)$. Clancy 2016 noted a similar outcome, showing a $50 \%$ acute exacerbation event reduction in hospital admissions following an acute exacerbation in the vaccine group ( $P$ $=0.047$ )

Any associated adverse side effects from the NTHi vaccination, measurable from symptomology and participant reports

There was no clear definition of what constituted an adverse effect and therefore no consistency between the studies' reporting of adverse events. For example, Tandon 1991 included increase of dyspnoea and cough as an adverse event, while Clancy 2016 reported mortality as a severe adverse event. None of the trials reported methods used for monitoring adverse events. There is thus potentially an under-reporting of less severe side effects. We could reach no clear comparisons or conclusions regarding 
any association between adverse effects and therapeutic effect. The adverse effects presented in the trials may well have been attributable to the significant comorbidity of the participant rather than to the vaccine. To discern whether these symptoms or adverse effects were true side effects of the vaccine or whether they were sequelae of the participant's disease process was not possible in this review due to the lack of primary study data.

\section{Quality of life}

Only two studies reported quality of life (QoL) measures (Clancy 2016; Tandon 1991), and these trials used different measurement tools, limiting the comparisons that could be made between the results. It is also notable that, by nature, the measurement of quality of life is subjective and difficult to quantify; neither study provided further data and information regarding which aspect of QoL was most improved. Nonetheless, both trials reported at least a two-point improvement in participant QoL in the vaccinated group versus the placebo group. Improvement in QoL was based on overall clinical condition assessed at the start of the trial and at set points during the trial. These intervals differed slightly between the two trials, with Tandon 1991 measuring at six months and Clancy 2016 measuring at three and six months. Clancy 2016 did not provide data on QoL for participants over 65 years of age.

\section{Overall completeness and applicability of evidence}

Although the numbers and sizes of the studies were low, all of the trials included participants with established COPD or chronic bronchitis. Clancy 2016 was the only study with sufficient sample size to conduct subgroup analyses assessing the effects of the vaccine in people less than 65 years of age. The majority of studies (with the exception of Lehmann 1991, which was conducted in Papua New Guinea) were conducted in an Australian population. However, trial length and follow-up periods varied from three to 12 months among the trials. The majority of the studies administered the HI-164 oral vaccine enteric-coated tablets (two per day), each of which contained $45 \mathrm{mg}$ active substance of formalininactivated NTHi, which was compared with enteric-coated placebo tablets (with the exception of Clancy 1985, which used a sodium tauroglycocholate substitute for the placebo). All studies had comparable objectives assessing the effect of the vaccine on acute COPD exacerbations.

We consider the results of this review to be applicable to people with established COPD.

\section{Quality of the evidence}

Overall, the methodological quality of the trials was acceptable, with most trials reporting methods of random sequence generation and allocation concealment sufficiently to assess them as adequate. The greatest limitation of the included studies was that of the six trials, one was by far the largest in terms of included population. The smaller studies were underpowered, and even when pooling the five smaller studies, their weighting was inferior to that of the one larger trial (Clancy 2016).

The assessment of primary outcomes of acute exacerbations was carried out through respiratory questionnaires, which are subjective, instead of using objective measures such as spirometry. Secondary outcomes such as $H$ influenzae colonisation and antibiotic use are more objective but may be difficult to measure.
Studies had low rates of loss to follow-up, and attrition rates were low and equal in both arms of the trials.

We found a moderate degree of heterogeneity in this metaanalysis, specifically in the outcome measuring the number of acute exacerbations of COPD $\left(I^{2}=57 \%, P=0.04\right)$. Clancy 1985 appears to contribute most to the heterogeneity; its exclusion from the analysis dramatically reduces heterogeneity $\left(I^{2}=24 \%, \mathrm{P}=\right.$ 0.26 ) and can likely be attributed to the study's reported result of only one exacerbation in the vaccinated group. Nonetheless, the exclusion of Clancy 1985 from the meta-analysis did not appear to have a significant impact on the overall result, given the small study size of approximately 30 participants and the robustness of the data sourced from the remaining studies.

\section{Potential biases in the review process}

Two review authors independently conducted all data selection and extraction, with a third review author acting as an arbiter, in order to minimise the risk of error and bias. One of the review authors (AC) was involved as an investigator in four of the six included trials (Clancy 1985; Clancy 1990; Clancy 2016; Lehmann 1991), but not involved in the data extraction and analysis in the review in order to reduce interpretation bias.

It is possible that despite extensive searching we may have missed a trial. However, this is very unlikely as one of the review authors is a world-renowned expert in the field and has consulted his extensive network to search for additional unpublished data. We are therefore confident that we have captured all available evidence in this review.

\section{Agreements and disagreements with other studies or reviews}

This is an update of a previously withdrawn Cochrane review of the same title (Foxwell 2006). The authors of the previous review concluded that the vaccine was efficacious in reducing 20\% to $30 \%$ of acute exacerbations in COPD patients and supported its use clinically. They also concluded that there was a need for larger clinical trials to assess longer-term prognosis. Since publication of the previous review a new trial with a substantially larger population has been published (Clancy 2016), and we have been able to include this in our updated meta-analysis. As a result of the inclusion of this large trial, the validity of the review has increased and the conclusions have changed substantially.

\section{AUTHORS' CONCLUSIONS}

\section{Implications for practice}

This review analysed six trials of monobacterial whole, killed, non-typeable Haemophilus influenzae (NTHi) vaccine in people experiencing recurrent acute exacerbations of chronic obstructive pulmonary disease (COPD). Our results do not support the use of the vaccine in reducing the number and severity of exacerbations.

\section{Implications for research}

Future trials should address the long-term effects of the NTHi oral vaccine. It would be useful to further assess outcomes at both 12 months and two years following the initial vaccination, alongside gathering data on mortality, age, and other contributing factors. It may also be useful to assess the effect of regular (seasonal) 
vaccination over a longer period of time. Careful standardisation of the measurement protocols is necessary for consistent analyses of outcomes including number of acute infective exacerbations, severity of exacerbations, carriage levels of $H$ influenzae and associated microbiology, hospital admissions, and prescription of antibiotics and corticosteroids. As polymerase chain reaction (PCR) is becoming more widely used in the diagnosis of infection, it may have a role in future research given the limitations of cultures, especially for micro-organisms such as $H$ influenzae, which are difficult to serotype. Future studies should more clearly assess and consider the use of antibiotics and steroids in COPD patients with $H$ influenzae, as these are common therapies that have a significant influence on mortality and morbidity, alongside bronchodilators, oxygen therapy, and ventilatory support.

The concept that COPD is a chronic condition with a peak incidence of diagnosis in people between 50 and 60 years of age means that patients included in studies already have well-established airway disease. Whilst the inclusion criteria for this review and trials concerning this vaccine specified those already diagnosed with COPD, it is equally important to assess the potential benefits of vaccinating people with a predisposition to developing COPD (e.g. younger populations of heavy smokers with mild airway disease that have not yet reached a chronic condition). Future research should therefore also be directed at assessing the effects of $H$ influenzae oral vaccination in high-risk populations not yet diagnosed with COPD, as a means of establishing the prophylactic capabilities of such a vaccine. Furthermore, future studies should consider subgroup analysis between younger versus older participants to determine if there are possible benefits of earlier immunisation.

The projected annual cost of COPD in the United States will increase from USD 176.8 to USD 832.9 billion in the next 20 years, with the majority of direct costs attributed to acute exacerbations (Lee 2006). As COPD is a non-curable disease, any cost-effective intervention to prevent exacerbations would be worth further research, considering the rising global prevalence and financial burden of treatment on the health system.

\section{ACKNOWLEDGEMENTS}

The first publication of this review was withdrawn (Foxwell 2006); we would therefore like to acknowledge the work of the previous authors: Foxwell AR, Cripps AW, Dear KBG.

The authors would also like to acknowledge the assistance of Emeritus Professor Robert Clancy of Newcastle University and Dr Phillips Comans of Bioxyne Pty Ltd for providing unpublished data from the Clancy 2016 trial for analysis. Finally, we wish to thank the following referees for commenting on the draft review: Theresa Wrangham, Marie Kakhu, Kerry-Ann O'Grady, An De Sutter, Teresa Neeman, and Taixiang Wu.

The authors would like to acknowledge the contribution of Ms Lesley Leong who co-author the updated protocol of this review.

The authors would like to acknowledge the contribution of $\mathrm{Dr}$ Hugh House who co-authored the previous updated version of this review. 


\section{RE F E R E N C E S}

\section{References to studies included in this review}

\section{Clancy 1985 \{published data only\}}

* Clancy R, Cripps A, Murree-Allen K, Yeung S, Engel M. Oral immunisation with killed Haemophilus influenzae for protection against acute bronchitis in chronic obstructive lung disease. Lancet 1985;2(8469-70):1395-7.

Clancy R, Cripps A, Pang G, Yeung S, Murree-Allen K. The paradox of immunisation against Haemophilus influenzaerelated endobronchitis: protection restricted to ingestion of 'non-adjuvenated' vaccine. Advances in Experimental Medicine and Biology 1987;216b:1759-64.

\section{Clancy 1990 \{published data only\}}

* Clancy RL, Cripps AW. Protection against recurrent acute bronchitis after oral immunisation with killed Haemophilus influenzae. Medical Journal of Australia 1990;152(8):413-6.

Clancy 2016 \{published and unpublished data\}

Clancy R, Dunkley M. Age dependent protection following oral immunisation with inactivated non-typeable Haemophilus influenzae in chronic obstructive pulmonary disease. Newcastle University and Bioxyne Pty Ltd.

* Clancy R, Dunkley M, Sockler J, McDonald C. Multisite placebo-controlled randomised clinical trial to assess protection following oral immunisation with inactivated non-typeable Haemophilus influenzae in chronic obstructive pulmonary disease. Internal Medicine Journal 2016;46(4):684-93. [DOI: 10.1111/imj.13072]

Lehmann 1991 \{published data only\}

* Lehmann D, Coakley KJ, Coakley CA, Spooner V, Montgomery J, Michael A, et al. Reduction in the incidence of acute bronchitis by an oral Haemophilus influenzae vaccine in patients with chronic bronchitis in the highlands of Papua New Guinea. American Review of Respiratory Disease 1991;144(2):324-30.

\section{Tandon 1991 \{published data only\}}

Tandon MK. Double-blind control trial of oral immunisation trial with killed Haemophilus influenzae (Bronchostat) in elderly chronic obstructive airway disease patients. Australian and New Zealand Journal of Medicine Supplement 1990;19(5):650.

* Tandon MK, Gebski V. A controlled trial of a killed Haemophilus influenzae vaccine for prevention of acute exacerbations of chronic bronchitis. Australian and New Zealand Journal of Medicine 1991;21(4):427-32.

\section{Tandon 2010 \{published data only\}}

Philips M, Tandon M, Warterer G, Dunkley M, Clancy R. HI-164 an oral vaccine to non-typeable haemophilus influenzae reduces antibiotic use respiratory exacerbations and hospitalisations in patients with COPD. European Respiratory Journal 2007;30:224.

* Tandon M, Phillips M, Waterer G, Dunkley M, Comans P, Clancy R. Oral immunotherapy with inactivated nontypeable
Haemophilus influenzae reduces severity of acute exacerbations in severe COPD. Chest 2010;137(4):805-11.

\section{References to studies excluded from this review}

Clancy 2010 \{published data only\}

Clancy RL, Dunkley ML. Oral non-typeable Haemophilus influenzae enhances physiological mechanism of airways protection. Clinical \& Experimental Immunology 2010;161(1):127-33.

\section{References to studies awaiting assessment ACTRN12606000074594 \{published data only\}}

ACTRN12606000074594. A multi-centre, double blind, placebo controlled, prospective study to assess safety and efficacy of orally administered killed whole cell nontypeable Haemophilus influenzae (NTHi) HI-1-164 in preventing episodes of acute bronchitis in patients with moderate to severe airway disease. www.anzctr.org.au/Trial/Registration/TrialReview.aspx? ACTRN=12606000074594 2013.

\section{ACTRN12606000076572 \{published data only\}}

ACTRN12606000076572. A multi-centre, double blind, placebo controlled, prospective study to assess safety and efficacy of orally administered killed whole cell nontypeable Haemophilus influenzae (NTHi) HI-1-164 in preventing episodes of acute bronchitis in patients with mild to moderate airway disease. www.anzctr.org.au/Trial/Registration/TrialReview.aspx?id=1121 2013.

\section{Additional references}

Albert 2011

Albert RK, Connett J, Bailey WC, Casaburi R, Cooper JA Jr, Criner GJ, et al. Azithromycin for prevention of exacerbations of chronic obstructive pulmonary disease. New England Journal of Medicine 2011;365:689-98.

\section{Atkins 2004}

Atkins D, Best D, Briss PA, Eccles M, Falck-Ytter Y, Flottorp S, et al. GRADE Working Group. Grading quality of evidence and strength of recommendations. BMJ 2004;328(7454):1490.

\section{Butt 1990}

Butt HL, Clancy RL, Cripps AW, Murree-Allen K, Saunders NA, Sutherland $\mathrm{D}$, et al. Bacterial colonisation of the respiratory tract in chronic bronchitis. Australian and New Zealand Journal of Medicine 1990;20(1):35-8.

\section{Clancy 2011}

Clancy R, Dunkley M. Acute exacerbations in COPD and their control with oral immunisation with nontypeable Haemophilus influenzae. Frontiers in Immunology 2011;2:7. 


\section{Collet 1997}

Collet JP, Shapiro S, Ernst P, Renzi P, Ducruet T, Robinson A, et al. Effects of an immunostimulating agent on acute exacerbations and hospitalizations in patients with chronic obstructive pulmonary disease. American Journal of Respiratory and Critical Care Medicine 1997;156(6):1719-24.

\section{Foxwell 1998a}

Foxwell AR, Kyd J, Cripps A. Nontypeable Haemophilus influenzae: pathogenesis and prevention. Microbiology and Molecular Biology Reviews 1998;62(2):294-308.

\section{GOLD 2011}

Global Initiative for Chronic Obstructive Lung Disease. Pocket Guide to COPD Diagnosis, Management and Prevention. Revised. Bethesda: National Institutes of Health, 2011.

\section{GRADEpro GDT 2014 [Computer program]}

GRADE Working Group, McMaster University. GRADEpro GDT. Version accessed 2014. Hamilton (ON): GRADE Working Group, McMaster University, 2014.

\section{Herath 2013}

Herath A, Poole P. Prophylactic antibiotic therapy for chronic obstructive pulmonary disease (COPD). Cochrane Database of Systematic Reviews 2013, Issue 11. [DOI: 10.1002/14651858.CD009764.pub2]

\section{Higgins 2011}

Higgins JPT, Green S (editors). Cochrane Handbook for Systematic Reviews of Interventions Version 5.1.0 (updated March 2011). The Cochrane Collaboration, 2011. Available from handbook.cochrane.org.

\section{Lee 2006}

Lee TA, Sullivan ST, Buist AS. Estimating the future economic burden of COPD. ATS Proceedings 2006;3:A598.

\section{Lefebvre 2011}

Lefebvre C, Manheimer E, Glanville J. Chapter 6: Searching for studies. In: Higgins JPT, Green S (editors). Cochrane Handbook for Systematic Reviews of Interventions Version 5.1.0 (updated March 2011). The Cochrane Collaboration, 2011. Available from handbook.cochrane.org.

\section{Longo 2011}

Longo D, Fauci A, Kasper D, Hauser S, Jameson J, Loscalzo J. Harrison's Principles of Internal Medicine. 18th Edition. Vol. 1 \& 2, New York: McGraw-Hill, 2011.

\section{Macfarlane 2001}

Macfarlane J, Holmes W, Gard P. Prospective study of the incidence, aetiology and outcome of adult lower respiratory tract illness in the community. Thorax 2001;56(2):109-14. [DOI: 10.1136/thorax.56.2.109]

\section{Murphy 1992}

Murphy T, Sethi S. Bacterial infection in chronic obstructive pulmonary disease. American Review of Respiratory Disease 1992;148:1067-83.

\section{Otczyk 2010}

Otczyk DC, Cripps AW. Mucosal immunization: a realistic alternative. Human Vaccines 2010;6(12):1-29.

\section{Otczyk 2011}

Otczyk D, Clancy R, Cripps A. Haemophilus influenzae and smoking-related obstructive airways disease. International Journal of Chronic Obstructive Pulmonary Disease 2011;6:345-51.

\section{RevMan 2014 [Computer program]}

Nordic Cochrane Centre, The Cochrane Collaboration. Review Manager 5 (RevMan 5). Version 5.3. Copenhagen: Nordic Cochrane Centre, The Cochrane Collaboration, 2014.

\section{Van Alphen 1995}

Van Alphen L, Jansen H, Dankert J. Virulence factors in the colonisation and persistence of bacteria in the airway. American Journal of Respiratory and Critical Care Medicine 1995;151:2094-100.

\section{WHO 2013}

World Health Organization. Chronic obstructive pulmonary disease. www.who.int/respiratory/copd/en/ 2013 (accessed 25 April 2014).

\section{References to other published versions of this review \\ Foxwell 1998b}

Foxwell AR, Cripps AW. Monobacterial whole killed cell Haemophilus influenzae oral vaccine against acute bronchitis. Cochrane Database of Systematic Reviews 1998, Issue 3. [DOI: 10.1002/14651858.CD005862]

\section{Foxwell 2000}

Foxwell AR, Cripps AWC. Haemophilus influenzae oral vaccination against acute bronchitis. Cochrane Database of Systematic Reviews 2000, Issue 1. [DOI: 10.1002/14651858.CD001958]

\section{Foxwell 2003}

Foxwell AR, Cripps AW, Dear KBG. Haemophilus influenzae oral whole cell vaccination for preventing acute exacerbations of chronic bronchitis. Cochrane Database of Systematic Reviews 2003, Issue 3. [DOI: 10.1002/14651858.CD001958]

\section{Foxwell 2006}

Foxwell AR, Cripps AW, Dear KBG. Haemophilus influenzae oral whole cell vaccination for preventing acute exacerbations of chronic bronchitis. Cochrane Database of Systematic Reviews 2006, Issue 4. [DOI: 10.1002/14651858.CD001958.pub2]

\section{Teo 2012}

Teo EK, Leong L, Purchuri SN, House H, Lockhart K, Pushparajah J, et al. Haemophilus influenzae oral vaccination for preventing acute exacerbations of chronic bronchitis and chronic obstructive pulmonary disease. Cochrane Database of Systematic Reviews 2012, Issue 8. [DOI: 10.1002/14651858.CD010010] 


\section{Teo 2014}

Teo E, House H, Lockhart K, Purchuri S, Pushparajah J, Cripps AW, et al. Haemophilus influenzae oral vaccination for preventing acute exacerbations of chronic bronchitis and chronic obstructive pulmonary disease. Cochrane

\section{CHARACTERISTICS OF STUDIES}

Characteristics of included studies [ordered by study ID]

\section{Clancy 1985}

\begin{tabular}{|c|c|}
\hline Methods & Double-blind, placebo-controlled, prospective RCT over a 3-month winter period in 1983 \\
\hline \multirow[t]{2}{*}{ Participants } & $\begin{array}{l}50 \text { patients from Royal Newcastle Hospital with COPD not taking corticosteroids or immunosuppres- } \\
\text { sants }\end{array}$ \\
\hline & Mean age of all participants: 65.5 \\
\hline Interventions & $\begin{array}{l}\text { NTHi vaccine and } 2 \text { placebo arms (enteric-coated glucose tablets or } 25 \mathrm{mg} \text { sodium tauroglycocholate). } \\
3 \text { courses of tablets were taken at } 0,28,56 \text { days. Each course was } 2 \text { tablets taken before breakfast on } 3 \\
\text { consecutive days. }\end{array}$ \\
\hline \multirow[t]{3}{*}{ Outcomes } & 1. Number of lower respiratory infections \\
\hline & 2. Haemophilus influenzae isolation \\
\hline & 3. Salivary antibodies \\
\hline \multirow[t]{3}{*}{ Notes } & $\begin{array}{l}\text { Many participants were taking antibiotics and bronchodilator agents but were not taking steroids or } \\
\text { immunosuppressants. }\end{array}$ \\
\hline & Ciba-Geigy (Australia) was cited for financial assistance in the Discussion. \\
\hline & Trial was conducted at the Royal Newcastle Hospital. \\
\hline
\end{tabular}

\section{Risk of bias}

Bias Authors' judgement Support for judgement

Random sequence genera- High risk tion (selection bias)

Randomisation was completed independently by a "Dr Smith" who kept the trial code allocations privately; how randomisation was performed was not disclosed. Whilst Dr Smith is not one of the trial authors, the exact nature of their relationship with the study is unknown. Randomisation in $1 \mathrm{arm}$ had a very uneven male-to-female ratio

\begin{tabular}{lll}
\hline $\begin{array}{l}\text { Allocation concealment } \\
\text { (selection bias) }\end{array}$ & Unclear risk & No information provided \\
\hline $\begin{array}{l}\text { Blinding of participants } \\
\begin{array}{l}\text { and personnel (perfor- } \\
\text { mance bias) } \\
\text { All outcomes }\end{array}\end{array}$ & Low risk & $\begin{array}{l}\text { For each participant with an acute upper and lower respiratory infection, an } \\
\text { infection questionnaire was completed by doctors who were not involved with } \\
\text { the study and had no knowledge of the participant's test group }\end{array}$ \\
\hline $\begin{array}{l}\text { Blinding of outcome as- } \\
\text { sessment (detection bias) } \\
\text { All outcomes }\end{array}$ & Low risk & $\begin{array}{l}\text { 1. Infection questionnaire with an independent doctor with no knowledge of } \\
\text { test group }\end{array}$ \\
& $\begin{array}{l}\text { 2. Sputum cultures collected to detect } H \text { influenzae involvement objectively } \\
\text { 3. Blood tests collected to assess salivary antibodies objectively }\end{array}$
\end{tabular}

Incomplete outcome data Low risk (attrition bias)
Database of Systematic Reviews 2014, Issue 9. [DOI:

10.1002/14651858.CD010010.pub2]

* Indicates the major publication for the study 
Clancy 1985 (Continued)

All outcomes

Selective reporting (re- Low risk Nil

porting bias)

Nil

Other bias Low risk Nil

Clancy 1990

\begin{tabular}{ll}
\hline Methods & Single-blind RCT \\
\hline Participants & 6-month study on Australians recruited during winter 1986 through radio station advertisement \\
& Mean age of 47.4 in the vaccine arm and 46.3 in the placebo arm \\
\hline Interventions & Oral vaccination with killed NTHi and placebo with glucose; both were enteric-coated \\
\hline Outcomes & $\begin{array}{l}\text { 1. Total number of episodes of acute bronchitis } \\
\text { 2. Number of episodes of acute wheezy bronchitis } \\
\text { 3. Reduction in antibiotic use }\end{array}$ \\
\hline Notes & $\begin{array}{l}\text { Participants were assessed on admission to trial and at } 3 \text { and } 6 \text { months during the trial. Most partici- } \\
\text { pants had previously unrecognised smoking-related chronic lung disease. } 72 \% \text { smokers and } 58 \% \text { had } \\
\text { chronic bronchitis. Participant admission criteria were }>3 \text { episodes of acute bronchitis (cough produc- } \\
\text { tive with sputum) over previous } 2 \text { years and an absence of chronic lung disease determined at clinical } \\
\text { interview }\end{array}$
\end{tabular}

Trial was conducted as joint research at the Royal Newcastle Hospital and Macquarie University

There was no disclosure of financial assistance

\section{Risk of bias}

\begin{tabular}{lll} 
Bias & Authors' judgement & Support for judgement \\
\hline $\begin{array}{l}\text { Random sequence genera- } \\
\text { tion (selection bias) }\end{array}$ & Low risk & $\begin{array}{l}\text { Participants were coded and randomised by an independent third party into } \\
\text { 2 groups. } 40 \text { participants were admitted to study; } 37 \text { completed the 6-month } \\
\text { trial. Randomisation gave well-matched treatment groups, which were equal } \\
\text { at baseline measurement. There was no significant reduction in the number of } \\
\text { participants suffering from an episode of acute bronchitis }\end{array}$
\end{tabular}

\begin{tabular}{lll}
\hline $\begin{array}{l}\text { Allocation concealment } \\
\text { (selection bias) }\end{array}$ & High risk & $\begin{array}{l}\text { Participants were allocated to the intervention group based on periods of } \\
\text { acute bronchitis that had been assessed by a nurse practitioner using an infec- } \\
\text { tion questionnaire, which may have room for subjectivity }\end{array}$ \\
\hline $\begin{array}{l}\text { Blinding of participants } \\
\begin{array}{l}\text { and personnel (perfor- } \\
\text { mance bias) }\end{array}\end{array}$ & High risk & $\begin{array}{l}\text { Medication had the same regimen and administration for both groups. Partici- } \\
\text { pants in the treatment arm were given the active preparation, each tablet con- } \\
\text { taining } 10 \text { x killed NTHi. Participants in the placebo arm were given a prepa- } \\
\text { ration containing glucose. Both were given in the form of } 2 \text { enteric-coated } \\
\text { tablets before breakfast on each of } 3 \text { consecutive days and repeated at } 28 \text { and } \\
56 \text { days. However, only participants were blinded in this study (single-blinded) }\end{array}$ \\
\hline $\begin{array}{l}\text { Blinding of outcome as- } \\
\text { sessment (detection bias) } \\
\text { All outcomes }\end{array}$ & Low risk & $\begin{array}{l}\text { 1. A questionnaire was used to diagnose acute bronchitis and the side effects of } \\
\text { the vaccine, which may be subjective according to the marker. However, the } \\
\text { questionnaire did include a detailed range of signs/symptoms to be support- } \\
\text { ed with routine haematological, biochemical, and immunological test results } \\
\text { (including a throat swab and Gram staining to validate the sputum) }\end{array}$ \\
\hline
\end{tabular}

Haemophilus influenzae oral vaccination for preventing acute exacerbations of chronic bronchitis and chronic obstructive pulmonary 
2. The differentiation of a wheeze from a normal acute bronchitis event is not clearly defined

3. Antibiotic use was measured objectively

Incomplete outcome data Low risk (attrition bias)

All outcomes
All participants were accounted for. 3 participants dropped out from the study: 2 from the placebo arm, 1 from the active arm due to poor compliance

\begin{tabular}{lll}
\hline $\begin{array}{l}\text { Selective reporting (re- } \\
\text { porting bias) }\end{array}$ & Low risk & Nil \\
\hline Other bias & Low risk & Nil \\
\hline
\end{tabular}

Clancy 2016

\begin{tabular}{|c|c|}
\hline Methods & Double-blind, placebo-controlled, prospective study for 9 months over the Australian winter of 2011 \\
\hline \multirow[t]{3}{*}{ Participants } & 320 moderate-severe COPD participants with $\mathrm{FEV}_{1}<60 \%$ predicted were recruited from 21 sites across \\
\hline & Australia \\
\hline & Mean age of participants in the vaccine arm was 71.2 and in the placebo arm was 67.9 \\
\hline Interventions & $\begin{array}{l}\mathrm{HI}-164 \text { oral vaccine enteric-coated tablets ( } 2 \text { per day) each of which contained } 45 \mathrm{mg} \text { active substance } \\
\text { of formalin-inactivated NTHi (HI-164) }\end{array}$ \\
\hline \multirow[t]{3}{*}{ Outcomes } & 1. Number of moderate-severe exacerbations \\
\hline & 2. Number of hospital admissions \\
\hline & 3. Number of corticosteroids and antibiotics prescribed \\
\hline
\end{tabular}

Notes

This was a multicentre trial conducted over various health districts across Australia

The trial does not cite any financial acknowledgement

\section{Risk of bias}

\begin{tabular}{|c|c|c|}
\hline Bias & Authors' judgement & Support for judgement \\
\hline $\begin{array}{l}\text { Random sequence genera- } \\
\text { tion (selection bias) }\end{array}$ & Unclear risk & $\begin{array}{l}\text { Does not disclose method. Randomisation mentioned but technique not spec- } \\
\text { ified }\end{array}$ \\
\hline $\begin{array}{l}\text { Allocation concealment } \\
\text { (selection bias) }\end{array}$ & Unclear risk & $\begin{array}{l}\text { Does not disclose method. Participants assumed to be blinded to the alloca- } \\
\text { tion process and to whether treatment or placebo received }\end{array}$ \\
\hline $\begin{array}{l}\text { Blinding of participants } \\
\text { and personnel (perfor- } \\
\text { mance bias) } \\
\text { All outcomes }\end{array}$ & Low risk & $\begin{array}{l}\text { Double-blinded study with same administration of medication for both treat- } \\
\text { ment and placebo arms. The treatment consisted of } 3 \text { courses of tablets; } \\
\text { each course was } 2 \text { tablets daily (before breakfast) for } 3 \text { consecutive days, with } \\
\text { courses repeated at day } 28 \text { and day } 56 \text {. Following randomisation, participants } \\
\text { attended site visits at weeks } 4,8,12 \text { and thereafter at } 4 \text {-week intervals un- } \\
\text { til week } 36 \text {. The placebo group had the same regimen, except with matched } \\
\text { placebo tablets }\end{array}$ \\
\hline $\begin{array}{l}\text { Blinding of outcome as- } \\
\text { sessment (detection bias) } \\
\text { All outcomes }\end{array}$ & Low risk & $\begin{array}{l}\text { Double-blinded study where acute episodes and background symptoms were } \\
\text { recorded by a questionnaire at all visits. To document change in day-to-day } \\
\text { symptoms, all participants used a diary and the St George's Respiratory Ques- } \\
\text { tionnaire for COPD patients (SGRQ-C) (version } 1.1 ; 11-12008 \text { ) was administered } \\
\text { at visit } 2 \text { (baseline), visit } 5 \text { (week 12), visit } 6 \text { (week 24), and visit } 7 \text { (week 36) }\end{array}$ \\
\hline
\end{tabular}

Haemophilus influenzae oral vaccination for preventing acute exacerbations of chronic bronchitis and chronic obstructive pulmonary 
Clancy 2016 (Continued)

Incomplete outcome data Low risk 320 participants were the ITT population, with a 10\% dropout rate anticipated (attrition bias) to ensure that greater than 270 completed the study as required by the power All outcomes analysis. Specifically, adverse event rates were similar in both groups: serious adverse events (placebo 33.5\%; active 38.5\%) with 4 deaths in the active group and 2 in the placebo group. None of these events was attributed to treatment modality

Selective reporting (re- Low risk Nil
porting bias)

Nil

Other bias Low risk Nil

Lehmann 1991

\begin{tabular}{|c|c|}
\hline Methods & RCT of 12 months' duration, double-blind, placebo-controlled \\
\hline \multirow[t]{6}{*}{ Participants } & Adults identified as suffering from chronic lung disease \\
\hline & 62 participants included \\
\hline & Setting: PNG highlands (under study surveillance) \\
\hline & Recruitment: nominated \\
\hline & Inclusion: productive cough fitting the time criteria for chronic lung disease \\
\hline & Mean age of participants in the vaccine arm was 52.6 and in the placebo arm was 53.7 \\
\hline \multirow[t]{3}{*}{ Interventions } & Oral inactivated vaccine containing 10 Haemophilus influenzae \\
\hline & Control: placebo, not specified \\
\hline & Duration: 2 tablets in the morning for 3 consecutive days at monthly intervals for 3 consecutive months \\
\hline \multirow[t]{3}{*}{ Outcomes } & 1. Incidence of acute exacerbations \\
\hline & 2. Bacterial carriage \\
\hline & 3. Adverse side effects of NTHi vaccine \\
\hline \multirow[t]{2}{*}{ Notes } & $\begin{array}{l}\text { An acute exacerbation is defined as an increase in the volume and purulence of sputum with no evi- } \\
\text { dence of respiratory distress, with or without chest pain or fever. This definition was consolidated with } \\
\text { clinical examination, respiratory questionnaire in Melasian pigeon English, spirometry, and sputum } \\
\text { samples }\end{array}$ \\
\hline & $\begin{array}{l}\text { Conducted at PNG Institute of Medical Research. Auspharm International Ltd cited in acknowledge- } \\
\text { ments for setting up study and ongoing support }\end{array}$ \\
\hline
\end{tabular}

\section{Risk of bias}

\begin{tabular}{lll}
\hline Bias & Authors' judgement & Support for judgement \\
\hline $\begin{array}{l}\text { Random sequence genera- } \\
\text { tion (selection bias) }\end{array}$ & Low risk & $\begin{array}{l}\text { The investigators describe appropriate random sequence generation using a } \\
\text { randomisation code for the courses of vaccine and placebo tablets }\end{array}$ \\
\hline $\begin{array}{l}\text { Allocation concealment } \\
\text { (selection bias) }\end{array}$ & Low risk & $\begin{array}{l}\text { Investigators enrolling participants could not foresee assignment, as randomi- } \\
\text { sation was performed by the third party "Auspharm International Ltd." in New } \\
\text { South Wales, Australia, accounting for the concealment of allocation }\end{array}$ \\
\hline
\end{tabular}


Lehmann 1991 (Continued)

Blinding of participants Low risk_ Double-blind trial. Blinding of participants and key study personnel ensured and personnel (perforand unlikely that the blinding could have been broken mance bias)

All outcomes

\begin{tabular}{|c|c|c|}
\hline $\begin{array}{l}\text { Blinding of outcome as- } \\
\text { sessment (detection bias) } \\
\text { All outcomes }\end{array}$ & Low risk & $\begin{array}{l}\text { Double-blind trial. The outcomes assessed in both groups were measured us- } \\
\text { ing the same questionnaire and a medical examination. Methods of ensuring } \\
\text { blinding of outcome assessment were not reported }\end{array}$ \\
\hline
\end{tabular}

All outcomes blinding of outcome assessment were not reported

Incomplete outcome data High risk (attrition bias)

All outcomes
Concluded from the trial report, there is no mention of ITT for participants lost to follow-up (8 from vaccine group and 3 from placebo group). This is substantial considering the small group sizes; it is possible that it had an effect on the outcome

\section{Selective reporting (re- Low risk} porting bias)

Study report fails to include results for a key outcome (prescription rate of antibiotics) that would be expected to have been reported for such a study, although the protocol is not available. However, all primary outcomes are reported

Other bias Low risk The study appears to be free of other sources of bias

Tandon 1991

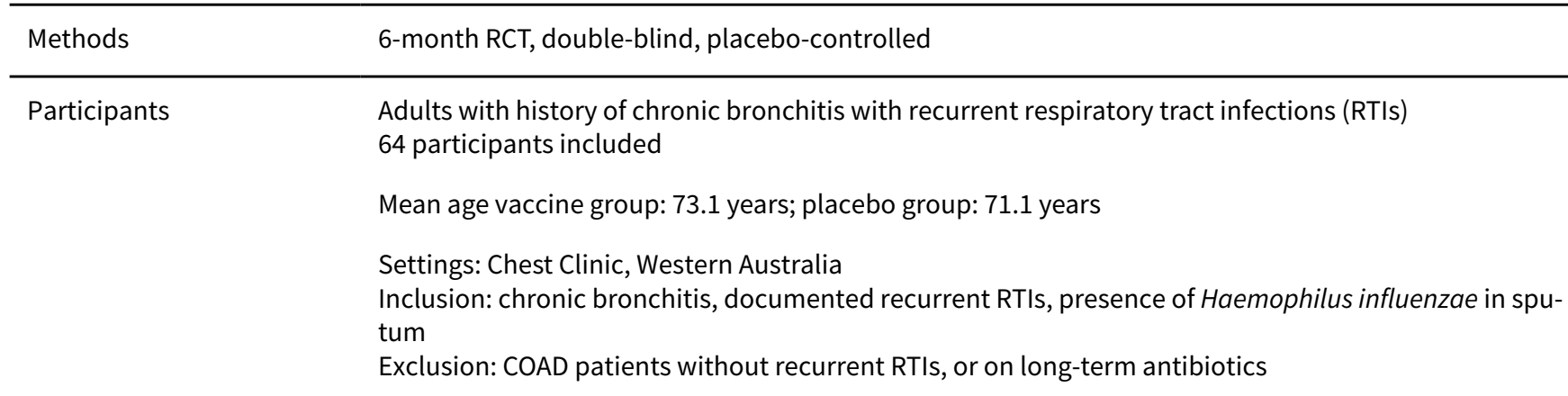

The oral vaccine contained 10 killed $H$ influenzae

Control: placebo was a lactose substitute for bacteria

Duration: 2 tablets in the morning for 3 consecutive days monthly for 3 consecutive months (day 0,28 , 56)

\begin{tabular}{l}
\hline Outcomes Incidence and occurrence of acute infections \\
2. NTHi carriage \\
3. Number of courses of antibiotics prescribed \\
4. Adverse effects of the vaccine \\
5. Quality of life (VAS score)
\end{tabular}

Notes
Acute exacerbation defined as: increase in volume and purulence of sputum usually associated with an increase in breathlessness or fever, or both requiring treatment with antibiotics
Exacerbation assessed by the trial authors using the following: physical exam, respiratory question- naire (ATS-DLD-78), lung function via spirometry, and sputum samples
Auspharm cited for providing Bronchostat and placebo tablets. Conducted at the repatriation hospital Western Australia


Tandon 1991 (Continued)

Risk of bias

\begin{tabular}{|c|c|c|}
\hline Bias & Authors' judgement & Support for judgement \\
\hline $\begin{array}{l}\text { Random sequence genera- } \\
\text { tion (selection bias) }\end{array}$ & Low risk & $\begin{array}{l}\text { The investigators describe a randomisation methodology in the sequence gen- } \\
\text { eration process, i.e. a randomisation chart }\end{array}$ \\
\hline $\begin{array}{l}\text { Allocation concealment } \\
\text { (selection bias) }\end{array}$ & Low risk & $\begin{array}{l}\text { Investigators enrolling participants could not foresee assignment because } \\
\text { pharmacy-controlled central allocation was used to conceal allocation }\end{array}$ \\
\hline $\begin{array}{l}\text { Blinding of participants } \\
\text { and personnel (perfor- } \\
\text { mance bias) } \\
\text { All outcomes }\end{array}$ & Low risk & $\begin{array}{l}\text { Double-blind. Blinding of participants and key study personnel ensured and } \\
\text { unlikely that the blinding could have been broken }\end{array}$ \\
\hline $\begin{array}{l}\text { Blinding of outcome as- } \\
\text { sessment (detection bias) } \\
\text { All outcomes }\end{array}$ & Low risk & $\begin{array}{l}\text { Method of ensuring blinding of outcome assessors is not reported. Respiratory } \\
\text { questionnaire was used to collect data for primary outcomes }\end{array}$ \\
\hline $\begin{array}{l}\text { Incomplete outcome data } \\
\text { (attrition bias) } \\
\text { All outcomes }\end{array}$ & Low risk & $\begin{array}{l}10 \text { participants lost to follow-up ( } 3 \text { in vaccine group and } 7 \text { in placebo group) } \\
\text { were analysed by intention-to-treat, which showed no significant differences. } \\
\text { For dichotomous outcome data, the proportion of missing outcomes com- } \\
\text { pared with the observed event risk was not enough to have a clinically relevant } \\
\text { impact on the intervention effect estimate }\end{array}$ \\
\hline $\begin{array}{l}\text { Selective reporting (re- } \\
\text { porting bias) }\end{array}$ & Low risk & The published report includes all expected outcomes \\
\hline Other bias & Low risk & The study appears to be free of other sources of bias \\
\hline
\end{tabular}

Tandon 2010

\begin{tabular}{ll} 
Methods & 4-month double-blind, placebo-controlled RCT carried out in winter in 4 centres in Western Australia \\
\hline Participants & $\begin{array}{l}\text { People with severe COPD defined by FEV } 1<50 \% \text { or }>2 \text { acute exacerbations per year for } 2 \text { consecutive } \\
\text { years } \\
\text { Mean age of participants in the vaccine arm was } 69.5 \text { and in the placebo arm was } 67.3\end{array}$ \\
\hline
\end{tabular}

Interventions $\quad$ HI-1640V: each tablet contained $45 \mathrm{mg}$ approximately 10 bacteria of formalin-inactivated NTHi provided as enteric-coated tablets

Control: enteric-coated placebo tablets containing excipients only

Duration: protocol stated that participants took 3 courses of 2 tablets in the morning for 3 consecutive days with courses repeated at 28 and 56 days

Outcomes
1. Number and severity of acute episodes (increase in volume and purulence of sputum)
2. Antibiotic courses
3. Sputum bacteriology and immune markers
4. Hospitalisations
5. Adverse effects

Multicentre trial. Most authors disclosed contributions from Hunter Immunology Ltd. 
Tandon 2010 (Continued)

Risk of bias

\begin{tabular}{|c|c|c|}
\hline Bias & Authors' judgement & Support for judgement \\
\hline $\begin{array}{l}\text { Random sequence genera- } \\
\text { tion (selection bias) }\end{array}$ & Unclear risk & $\begin{array}{l}\text { Participants were reportedly randomised, although the method of randomisa- } \\
\text { tion was not discussed. Baseline characteristics suggest that randomisation } \\
\text { was successful }\end{array}$ \\
\hline $\begin{array}{l}\text { Allocation concealment } \\
\text { (selection bias) }\end{array}$ & Unclear risk & $\begin{array}{l}\text { No information was provided about the procedure for protecting the randomi- } \\
\text { sation process so that the treatment to be allocated was not known before the } \\
\text { patient was entered into the study }\end{array}$ \\
\hline $\begin{array}{l}\text { Blinding of participants } \\
\text { and personnel (perfor- } \\
\text { mance bias) } \\
\text { All outcomes }\end{array}$ & Low risk & Double-blind trial \\
\hline $\begin{array}{l}\text { Blinding of outcome as- } \\
\text { sessment (detection bias) } \\
\text { All outcomes }\end{array}$ & Low risk & $\begin{array}{l}\text { Primary outcome was measured using a respiratory questionnaire. These sub- } \\
\text { jective data are prone to recall bias. Secondary outcomes were objectively } \\
\text { measured using bacterial colonisations and antibody titres }\end{array}$ \\
\hline $\begin{array}{l}\text { Incomplete outcome data } \\
\text { (attrition bias) } \\
\text { All outcomes }\end{array}$ & Low risk & $\begin{array}{l}\text { Participants were followed up for } 4 \text { months after completing the } 3 \text { courses. No } \\
\text { participants were lost to follow-up. Data surrounding withdrawal and discon- } \\
\text { tinuation from the study were well described }\end{array}$ \\
\hline $\begin{array}{l}\text { Selective reporting (re- } \\
\text { porting bias) }\end{array}$ & Low risk & The published report includes all expected outcomes \\
\hline Other bias & Low risk & No other sources of biases were identified \\
\hline
\end{tabular}

ATS-DLD-78: American Thoracic Society Division of Lung Disease questionnaire

COAD: chronic obstructive airways disease

COPD: chronic obstructive pulmonary disease

$\mathrm{FEV}_{1}$ : forced expiratory volume in one second

ITT: intention-to-treat

NTHi: non-typeable Haemophilus influenzae

PNG: Papua New Guinea

$\mathrm{RCT}$ : randomised controlled trial

RTI: respiratory tract infection

VAS: visual analogue scale

Characteristics of excluded studies [ordered by study ID]

\begin{tabular}{ll}
\hline Study & Reason for exclusion \\
\hline Clancy 2010 & $\begin{array}{l}\text { The participants and outcome measures of this study did not match this review's protocol. Partici- } \\
\text { pants were smokers with no clearly defined respiratory disease. Outcome measures were limited to } \\
\text { physiological markers as opposed to the clinical outcomes of this review }\end{array}$ \\
\hline
\end{tabular}

Characteristics of studies awaiting assessment [ordered by study ID]

\section{ACTRN12606000074594}

Methods
Participants will be randomly allocated to active tablets each containing $45 \mathrm{mg} \mathrm{HI}-1$-164-AS (inactivated non-typeable Haemophilus influenzae). Study medication (2 tablets) will be taken on days

Haemophilus influenzae oral vaccination for preventing acute exacerbations of chronic bronchitis and chronic obstructive pulmonary

Copyright $\odot 2017$ The Cochrane Collaboration. Published by John Wiley \& Sons, Ltd. 
ACTRN12606000074594 (Continued)

$1,2,3,29,30,31,57,58,59$. The live phase of the study will be of 8 months duration (March to October)

Participants
Both males and females, greater than or equal to 18 years of age, with moderate to severe airway disease

Total number of participants is 124 ; randomised to either active or placebo group

Interventions HI-1-164-AS (inactivated non-typeable Haemophilus influenzae) oral vaccine tablet

Outcomes

Primary outcomes: number of episodes of acute bronchitis during the study; proportion of participants experiencing an episode of acute bronchitis during the study; duration of episodes of acute bronchitis during the study; number of courses of antibiotics taken for treatment of acute episodes of bronchitis during the study

Secondary outcomes: NTHi-specific antibody; pharyngeal colonisation with $\mathrm{H}$ influenzae; presence of $H$ influenzae, Moraxella catarrhalis, Streptococcus pneumoniae, and Pseudomonas species in sputum; severity of episodes of acute bronchitis

\section{Notes}

It was planned in this trial that the analysis of the severity of episodes of acute bronchitis was to be based on the respiratory questionnaires completed by the participants at the time of each episode. However, insufficient respiratory questionnaires were completed during the study to allow for analysis of the data collected. In accordance with recent draft guidance for industry for developing drugs for treatment of COPD issued by the FDA in November 2007, assessment of modification or prevention of exacerbations of disease can include severity of exacerbations as a primary efficacy endpoint. This can be based on worsening of symptoms requiring changes in treatment or requiring urgent treatment or hospitalisation. On a post hoc basis, rates of hospitalisation, corticosteroid use, and a review of the medications used to treat the episodes of acute bronchitis were all analysed as measures of severity of episodes

\section{ACTRN12606000076572}

$\begin{array}{ll}\text { Methods } & \text { Participants will be randomly allocated to active tablets each containing } 45 \text { mg HI-1-164-AS (inac- } \\ \text { tivated non-typeable Haemophilus influenzae). Study medication ( } 2 \text { tablets) will be taken on days } \\ \text { 1, 2, 3, 29, 30, 31, 57, 58, 59. The live phase of the study will be of } 8 \text { months duration (March to Octo- } \\ \text { ber) }\end{array}$

Participants Both males and females, greater than or equal to 18 years of age, with mild to severe airway disease

Total number of participants is 124; randomised to either active or placebo group

Interventions HI-1-164-AS (inactivated non-typeable Haemophilus influenzae) oral vaccine tablet

Outcomes

Primary outcomes: number of episodes of acute bronchitis during the study; proportion of participants experiencing an episode of acute bronchitis during the study; duration of episodes of acute bronchitis during the study; number of courses of antibiotics taken for treatment of acute episodes of bronchitis during the study

Secondary outcomes: NTHi-specific antibody; pharyngeal colonisation with $\mathrm{H}$ influenzae; presence of $H$ influenzae, Moraxella catarrhalis, Streptococcus pneumoniae, and Pseudomonas species in sputum; severity of episodes of acute bronchiti

Notes

This trial is synonymous to ACTRN12606000074594, with the only difference to be found in the inclusion criteria of participants; this trial accepts patients with mild to severe airway disease (versus moderate to severe). However, there is no further specification or discussion on how the investiga- 
ACTRN12606000076572 (Continued)

tors discern the extent of airway disease in their study participants. Both studies enrolled participants on 7 March 2006 and were conducted simultaneously

COPD: chronic obstructive pulmonary disease

FDA: US Food and Drug Administration

NTHi: non-typeable Haemophilus influenzae

\section{DATA AND ANALYSES}

Comparison 1. Primary outcomes

\begin{tabular}{lllll}
\hline Outcome or subgroup title & No. of studies & $\begin{array}{l}\text { No. of partici- } \\
\text { pants }\end{array}$ & Statistical method & Effect size \\
\hline $\begin{array}{l}\text { 1 Exacerbations (number of exacerba- } \\
\text { tions/person) }\end{array}$ & 6 & 557 & $\begin{array}{l}\text { Rate Ratio (Random, 95\% } \\
\mathrm{Cl})\end{array}$ & $0.79[0.57,1.10]$ \\
\hline 2 Mortality (deaths during trial period) & 5 & 518 & $\begin{array}{l}\text { Odds Ratio (M-H, Fixed, 95\% } \\
\text { Cl) }\end{array}$ & $1.62[0.63,4.12]$ \\
\hline
\end{tabular}

Analysis 1.1. Comparison 1 Primary outcomes, Outcome 1 Exacerbations (number of exacerbations/person).

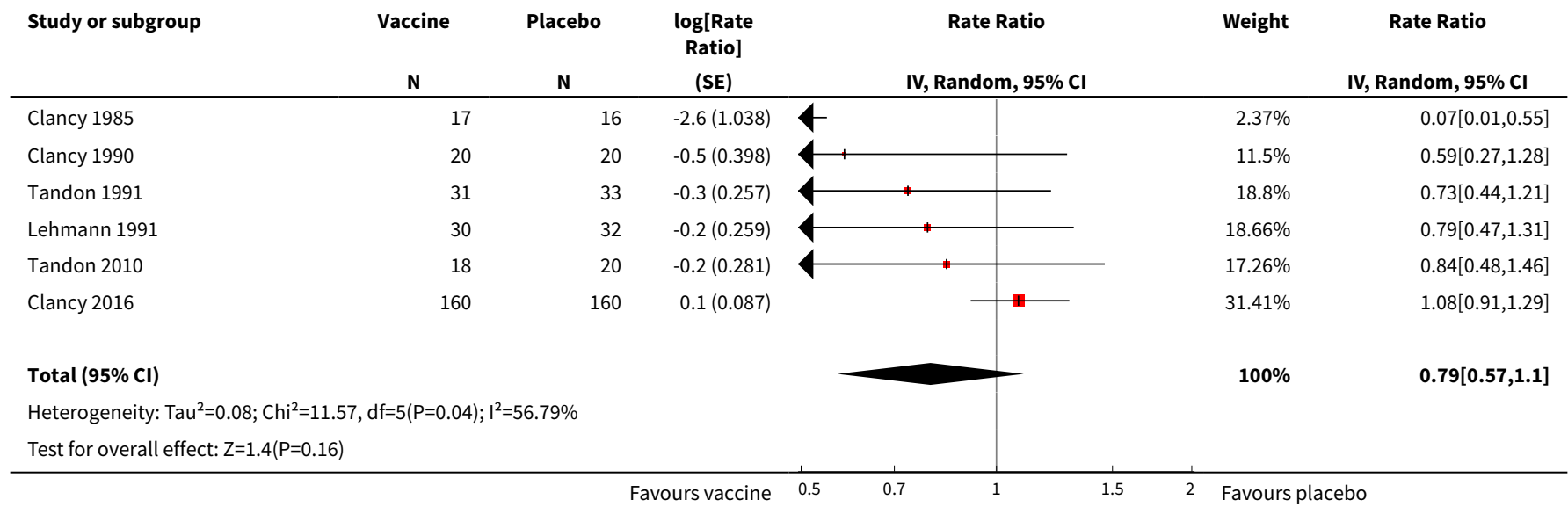

Analysis 1.2. Comparison 1 Primary outcomes, Outcome 2 Mortality (deaths during trial period).

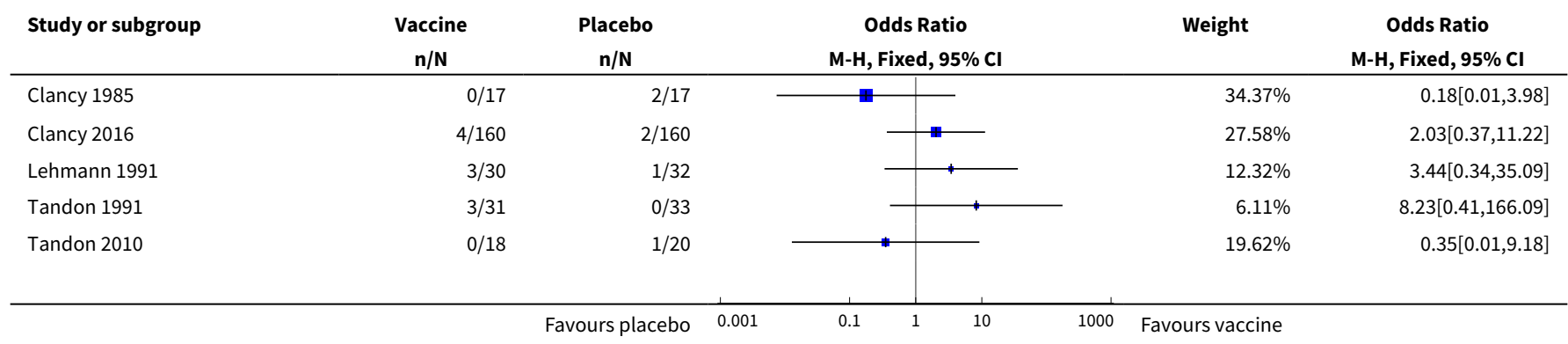




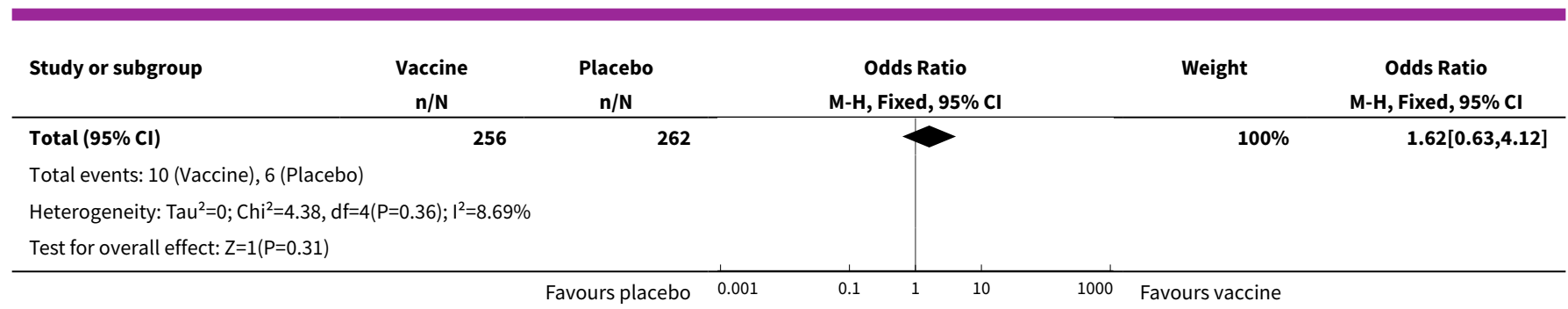

\section{Comparison 2. Secondary outcomes}

\begin{tabular}{lllll}
\hline Outcome or subgroup title & No. of studies & $\begin{array}{l}\text { No. of partici- } \\
\text { pants }\end{array}$ & Statistical method & Effect size \\
\hline $\begin{array}{l}1 \text { Prescriptions (number of courses/per- } \\
\text { son/year) }\end{array}$ & 3 & 142 & Rate Ratio (Fixed, 95\% Cl) & $1.81[1.35,2.44]$ \\
\hline $\begin{array}{l}\text { 2 Adverse events (number of adverse } \\
\text { events/person) }\end{array}$ & 4 & 484 & Rate Ratio (Fixed, 95\% Cl) & $1.43[0.70,2.92]$ \\
\hline
\end{tabular}

Analysis 2.1. Comparison 2 Secondary outcomes, Outcome 1 Prescriptions (number of courses/person/year).

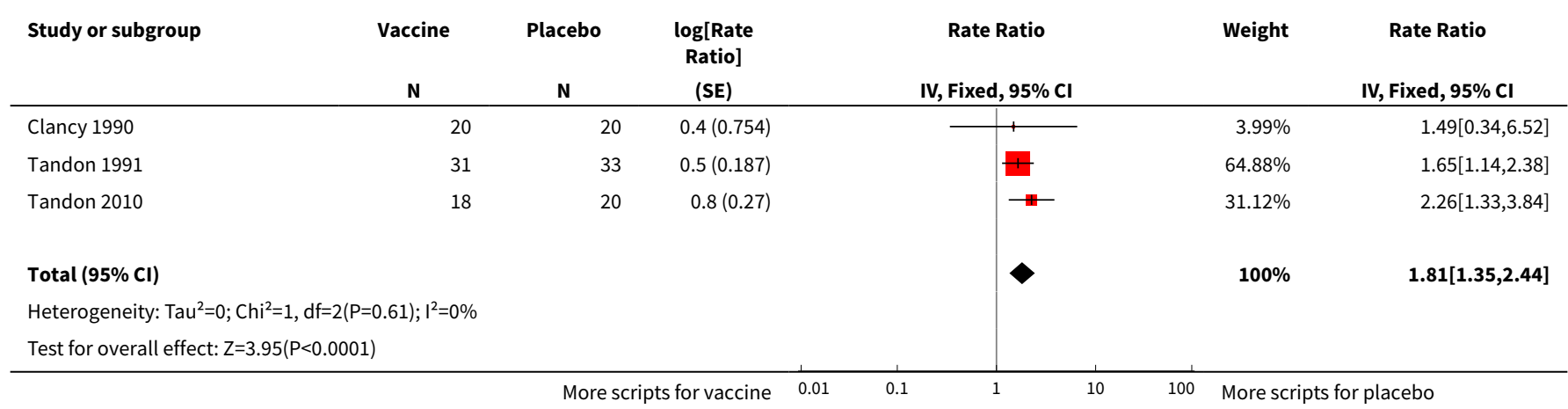

Analysis 2.2. Comparison 2 Secondary outcomes, Outcome 2 Adverse events (number of adverse events/person).

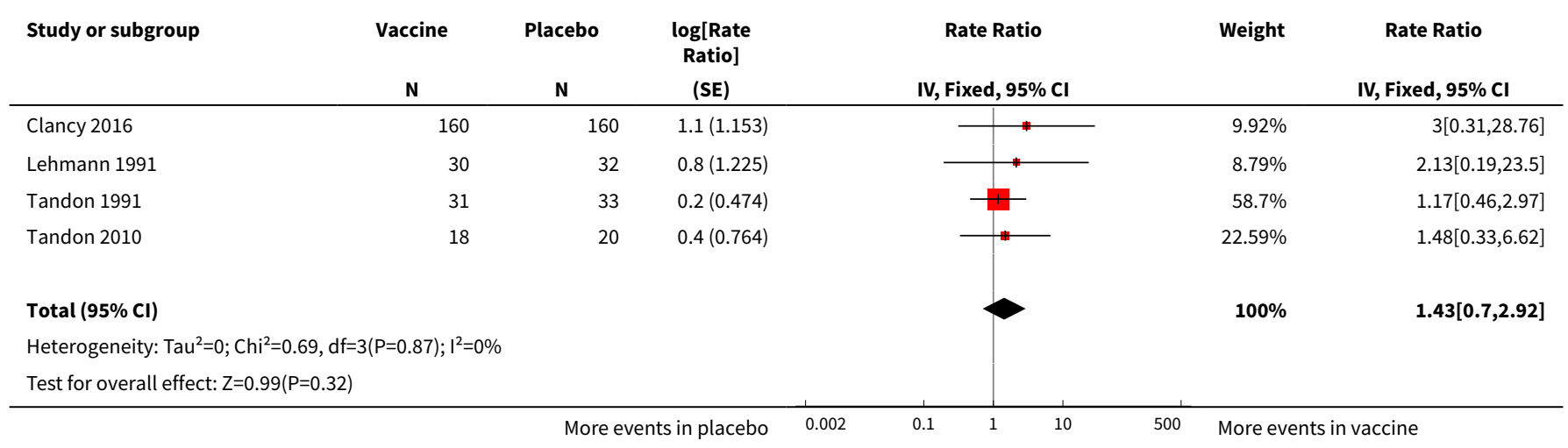


ADDITIONAL TABLES

Table 1. Rate estimates of acute exacerbations across included studies

\begin{tabular}{llll}
\hline Study & Vaccinated & Placebo & *Absolute rate difference \\
\hline Clancy 1985 & 0.256 & 0.272 & $0.016(-)$ \\
\hline Clancy 1990 & 1.000 & 1.700 & $0.700(-)$ \\
\hline Clancy 2016 & 0.717 & 0.767 & $0.050(-)$ \\
\hline Lehmann 1991 & 0.800 & 1.210 & $0.410(-)$ \\
\hline Tandon 1991 & 3.355 & 4.364 & $1.009(-)$ \\
\hline Tandon 2010 & 3.667 & 4.350 & $0.683(-)$ \\
\hline Overall mean & 1.633 & 2.111 & $0.478(-)$ \\
\hline
\end{tabular}

*Estimated rate of exacerbation calculated as number of exacerbations per person per year.

Refer to Analysis 1.1: Forest plot comparison and rate ratios for exacerbations.

Table 2. Rate estimates of antibiotic prescriptions across included studies

\begin{tabular}{llll}
\hline Study & Vaccinated & Placebo & *Absolute rate difference \\
\hline Clancy 1990 & 0.500 & 1.200 & $0.700(-)$ \\
\hline Tandon 1991 & 5.806 & 10.194 & $4.388(-)$ \\
\hline Tandon 2010 & 3.180 & 7.200 & $4.020(-)$ \\
\hline Overall mean & 3.162 & 6.198 & $3.036(-)$ \\
\hline
\end{tabular}

${ }^{\star}$ Estimated rate of antibiotic prescriptions calculated as number of antibiotic courses per person per year.

Refer to Analysis 2.1: Forest plot comparison and rate ratios for antibiotic prescriptions.

Table 3. Rate estimates of adverse events across included studies

\begin{tabular}{llll}
\hline Study & Vaccinated & Placebo & *Absolute rate difference \\
\hline Clancy 2016 & 0.008 & 0.025 & $0.017(-)$ \\
\hline Lehmann 1991 & 0.067 & 0.031 & $0.036(+)$ \\
\hline Tandon 1991 & 1.032 & 1.212 & $0.180(-)$ \\
\hline Tandon 2010 & 0.167 & 0.450 & $0.283(-)$ \\
\hline Overall mean & 0.319 & 0.430 & $0.111(-)$ \\
\hline
\end{tabular}

${ }^{\star}$ Estimated rate of adverse events calculated as number of adverse events per person per year. 
Refer to Analysis 2.2: Forest plot comparison and rate ratios for adverse events.

\section{APPENDICES}

\section{Appendix 1. MEDLINE and CENTRAL search strategy \\ MEDLINE (Ovid)}

1 exp Bronchitis/

2 bronchit*.tw.

3 exp Pulmonary Disease, Chronic Obstructive/

4 (chronic obstructive pulmonary disease ${ }^{\star}$ or chronic obstructive lung disease ${ }^{\star}$ ).tw.

5 Lung Diseases, Obstructive/

6 (copd or aecb).tw.

7 or $/ 1-6$

8 exp Haemophilus influenzae/

9 (haemophilus influenz* or "h. influenzae").tw.

10 (hemophilus or haemophilus).tw.

11 nthi.tw.

12 or/8-11

13 exp Vaccines/

14 exp Immunization/

15 Immunotherapy/

16 (vaccin ${ }^{\star}$ or immuni* or inoculat*).tw.

17 or/13-16

1812 and 17

19 Haemophilus Vaccines/

2018 or 19

217 and 20

\section{Appendix 2. Embase (Elsevier) search strategy}

\#27 \#18 AND \#26

\#26 \#21 NOT \#25

\#25 \#22 NOT \#24

\#24 \#22 AND \#23

\#23 'human'/de

\#22 'animal'/de OR 'nonhuman'/de OR 'animal experiment'/de

\#21 \#19 OR \#20

\#20 random*:ab,ti OR placebo*:ab,ti OR crossover*:ab,ti OR 'cross over':ab,ti OR allocat*:ab,ti OR trial:ti OR (doubl* NEXT/1 blind*):ab,ti

\#19 'randomized controlled trial'/exp OR 'single blind procedure'/exp OR 'double blind procedure'/exp OR 'crossover procedure'/exp

\#18 \#5 AND \#17

\#17 \#15 OR \#16

\#16 'haemophilus vaccine'/de

\#15 \#9 AND \#14

\#14 \#10 OR \#11 OR \#12 OR \#13

\#13 vaccin*:ab,ti OR immuni*:ab,ti OR inoculat*:ab,ti

\#12 'immunotherapy'/de

\#11 'immunization'/exp

$\# 10$ 'vaccine'/exp

\#9 \#6 OR \#7 OR \#8

\#8 haemophilus:ab,ti OR hemophilus:ab,ti

\#7 'haemophilus influezae':ab,ti OR 'h. influenzae':ab,ti OR nthi:ab,ti

\#6 'haemophilus influenzae'/exp

\#5 \#1 OR \#2 OR \#3 OR \#4

\#4 'chronic obstructive lung disease':ab,ti OR 'chronic obstructive pulmonary disease':ab,ti OR copd:ab,ti OR aecb:ab,ti

\#3 'chronic obstructive lung disease'/de

\#2 bronchit*:ab,ti

\#1 'bronchitis'/exp 


\section{Appendix 3. CINAHL (Ebsco) search strategy}

\section{S18 S6 and S17}

S17 S15 or S16

S16 (MH "HIB Vaccine")

S15 S9 and S14

$\mathrm{S} 14 \mathrm{~S} 10$ or $\mathrm{S} 11$ or $\mathrm{S} 12$ or $\mathrm{S} 13$

S13 TI (vaccin ${ }^{\star}$ or immuni* or inocul $\left.{ }^{\star}\right)$ OR AB $\left(\right.$ vaccin $^{\star}$ or immuni* or inocul*)

S12 (MH "Immunotherapy")

S11 (MH "Immunization+")

S10 (MH "Vaccines+")

S9 $\mathrm{S7}$ or $\mathrm{S} 8$

S8 TI (haemophilus or hemophilus or "h. influenzae" or nthi) OR AB (haemophilus or hemophilus or "h. influenzae" or nthi)

S7 (MH "Haemophilus Influenzae")

$\mathrm{S} 6 \mathrm{~S} 1$ or S2 or S3 or S4 or S5

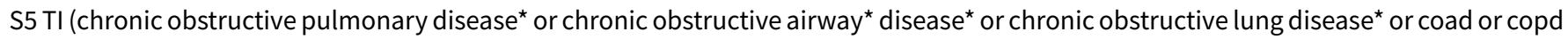
or aecb) OR AB (chronic obstructive pulmonary disease ${ }^{\star}$ or chronic obstructive airway ${ }^{\star}$ disease ${ }^{\star}$ or chronic obstructive lung disease ${ }^{\star}$ or coad or copd or aecb)

S4 (MH "Lung Diseases, Obstructive")

S3 (MH "Pulmonary Disease, Chronic Obstructive+")

S2 TI bronchit* OR AB bronchit*

S1 (MH "Bronchitis+")

\section{Appendix 4. LILACS (BIREME) search strategy}

Search > (MH:Bronchitis OR MH:C08.127.446\$ OR MH:C08.381.495.146\$ OR C08.730.099\$ OR Bronquitis OR Bronquite OR bronchit\$ OR MH:"Pulmonary Disease, Chronic Obstructive" OR "Chronic Obstructive Airway Disease" OR "Chronic Obstructive Lung Disease" OR "Chronic Obstructive Pulmonary Disease" OR COAD OR COPD OR MH:C08.381.495.389\$ OR "Obstrucción Crónica del Flujo Aéreo" OR "Obstrucción del Flujo Aéreo Crónica" OR "Enfermedad Obstructiva Crónica de las Vías Aéreas" OR "Enfermedad del Pulmón Crónica Obstructiva" OR "Enfermedad Pulmonar Crónica Obstructiva" OR EVOC OR EPOC OR "Neumopatía Obstructiva Crónica" OR DPOC OR "Obstrução Crônica do Fluxo Respiratório" OR "Obstrução do Fluxo Respiratório Crônica" OR "Doença Obstrutiva Crônica das Vias Aéreas" OR "Doença Obstrutiva Crônica do Pulmão" OR "Doença Obstrutiva Crônica Pulmonar" OR MH:"Lung Diseases, Obstructive" OR AECB) AND (((MH:"Haemophilus influenzae" OR "H. influenzae" OR haemophilus OR hemophilus OR nthi OR MH:B03.440.450.600.450.330\$ OR MH:B03.660.250.550.290.330\$) AND (MH:Vaccines OR Vacunas OR Vacinas OR vaccin\$ OR D20.215.894\$ OR MH:Immunization OR Inmunización OR Imunização OR MH:E02.095.465.425.400\$ OR MH:E05.478.550\$ OR MH:N02.421.726.758.310\$ OR MH:N06.850.780.200.425\$ OR MH:N06.850.780.680.310\$ OR MH:SP2.026.182.113\$ OR MH:SP4.001.002.015.049\$ OR MH:SP8.946.819.838\$ OR "Estimulación Inmunológica" OR Inmunoestimulación OR "Sensibilización Inmunológica" OR Variolación OR Variolización OR Inmunizaciones OR "Estimulação Imunológica" OR Imunoestimulação OR "Sensibilização Imunológica" OR Variolação OR Imunizações OR immuni\$ OR MH:Immunotherapy OR Inmunoterapia OR Imunoterapia OR inocul\$)) OR (MH:"Haemophilus Vaccines" OR "Vacunas contra Haemophilus" OR "Vacinas Anti-Haemophilus"))

\section{Appendix 5. Web of Science (Thomson Reuters) search strategy}

\begin{tabular}{|l|l|}
\hline \# 5 & 18 \\
\hline$\# 4$ & \\
\hline & $1,371,720$ \\
\hline$\# 3$ & 117 \\
\hline & \\
\hline$\# 2$ & 5,029 \\
\hline & \\
\hline
\end{tabular}


WHAT'S NEW

\begin{tabular}{lll}
\hline Date & Event & Description \\
\hline 9 January 2017 & $\begin{array}{l}\text { New citation required but conclusions } \\
\text { have not changed }\end{array}$ & Our conclusions remain unchanged and up-to-date. \\
\hline 9 January 2017 & New search has been performed & $\begin{array}{l}\text { Searches updated. We identified 199 records but none were in- } \\
\text { cluded in the meta-analyses. One study awaiting classification } \\
\text { has since been published (ACTRN12610000916044 2013 has } \\
\text { been published as Clancy 2016). There are otherwise two studies } \\
\text { awaiting classification that remain in the trial phase. }\end{array}$ \\
\hline
\end{tabular}

\section{CONTRIBUTIONS OF AUTHORS}

All of the authors contributed to the drafting of the protocol. Professor Mieke van Driel and Professor Allan Cripps provided expert and methodological advice, including extensive help and support during the drafting of the protocol and review.

\section{DECLARATIONS OF INTEREST}

Edward Teo has no potential conflicts of interest to declare.

Kathleen Lockhart has no potential conflicts of interest to declare.

Sai Navya Purchuri has no potential conflicts of interest to declare.

Jennifer Pushparajah has no potential conflicts of interest to declare.

Professor Allan Cripps was involved in the initial animal work and conduct of the four trials in Newcastle, Australia. The commercial product, Bronchostat, which originated from these trials, is no longer commercially available. The commercial companies Auspharm International Ltd and subsequently Cortecs International Ltd have ceased trading and were delisted from the Australian Stock Exchange (ASX) in 1991 and 1998, respectively. Prior to 1996, Professor Cripps acted as a consultant for both Auspharm International Ltd and Cortecs International Ltd. Hunter Immunology Ltd subsequently continued development of the oral whole-cell vaccine (HI-164). In 2004, Professor Cripps acquired a small stock holding in the company. In 2011, Hunter Immunology Ltd was acquired by Bioxyne Ltd, and Professor Cripps' shares were transferred to Bioxyne Ltd. Subsequently, in February 2014, Bioxyne Ltd sold to Mariposa Health Ltd the HI-164 Oral Vaccine project and all associated intellectual property. Should Mariposa Health Ltd successfully commercialise the vaccine, Mariposa Health Ltd has agreed to pay Bioxyne Ltd a royalty of up to $6.5 \%$ of gross revenue. Professor Cripps retains a small residual stock holding in Bioxyne Ltd. Professor Cripps has no stock holding in Mariposa Health Ltd. He has not received any honoraria, participated in expert testimony, or received any consultancy fees from either Mariposa Health Ltd or Bioxyne Ltd. Professor Cripps' potential conflicts of interest have been assessed by the Cochrane Funding and Arbitration Panel (reference number 150514/064) and considered of low risk. Mieke $L$ van Driel has no potential conflicts of interest to declare.

\section{SOURCES OF SUPPORT}

\section{Internal sources}

- Bond University, Australia.

- Griffith University, Australia.

- University of Queensland, Australia.

- Queensland Health Department, Australia.

- New South Wales Health Department, Australia.

- Cochrane Acute Respiratory Infections Group, Australia.

\section{External sources}

- No sources of support supplied 


\section{DIFFERENCES BETWEEN PROTOCOLAND REVIEW}

We have included risk ratios as a method of measuring the treatment effect for dichotomous data given as rates. We have amended the Data synthesis to reflect that we have also used the fixed-effect model to pool study data that reported events as rates.

Prescriptions of corticosteroids was not an outcome measure in any of the included studies and therefore not part of this review's analyses. However, participants were noted to have been prescribed steroids prior to commencing the trial and may have continued steroids or have been further prescribed steroids during the trial periods without clear reporting in the studies (this is discussed in the Summary of main results).

We added number of hospital admissions to Secondary outcomes as part of the assessment of the severity of exacerbations after post hoc analysis revealed that a number of studies had reported hospital admissions.

\section{INDEX TERMS}

\section{Medical Subject Headings (MeSH)}

Administration, Oral; Anti-Bacterial Agents [administration \& dosage]; Bronchitis, Chronic [mortality] [ ${ }^{\star}$ prevention \& control]; Disease

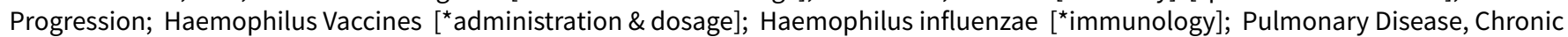
Obstructive [mortality] [ ${ }^{*}$ prevention \& control]; Randomized Controlled Trials as Topic; Secondary Prevention; Tablets, Enteric-Coated

\section{MeSH check words}

Adult; Aged; Aged, 80 and over; Humans; Middle Aged 